\title{
Malignant glioma: genetics and biology of a grave matter
}

\author{
Elizabeth A. Maher, ${ }^{1,2}$ Frank B. Furnari, ${ }^{7}$ Robert M. Bachoo, ${ }^{1,2,4}$ David H. Rowitch, ${ }^{3}$ \\ David N. Louis, ${ }^{5}$ Webster K. Cavenee, ${ }^{7,8}$ and Ronald A. DePinho ${ }^{2,6,9}$ \\ ${ }^{1}$ Center for Neuro-Oncology, ${ }^{2}$ Departments of Adult Oncology and ${ }^{3}$ Pediatric Oncology, Dana-Farber Cancer Institute; \\ ${ }^{4}$ Department of Neurology, Brigham and Women's Hospital; ${ }^{5}$ Department of Pathology and Neurosurgical Service, \\ Massachusetts General Hospital; ${ }^{6}$ Departments of Genetics and Medicine, Harvard Medical School, Boston, Massachusetts \\ 02115, USA; ${ }^{7}$ Ludwig Institute for Cancer Research, ${ }^{8}$ Department of Medicine, Center for Molecular Genetics, and Cancer \\ Center, University of California-San Diego, La Jolla, California 92037, USA
}

Malignant brain tumors strike deep into the psyche of those receiving and those delivering the diagnosis. Malignant gliomas, the most common subtype of primary brain tumors, are aggressive, highly invasive, and neurologically destructive tumors considered to be among the deadliest of human cancers. In its most aggressive manifestation, glioblastoma (GBM), median survival ranges from 9 to 12 months, despite maximum treatment efforts-a statistical fact that has changed little over several decades of technological advances in neurosurgery, radiation therapy, and clinical trials of conventional and novel therapeutics. Over the same time period, there has been an explosion of knowledge in cancer biology and basic science discovery that has fueled meaningful progress in the treatment of many common human cancers, including those of the breast, lung, and prostate. It is perplexing that therapies used effectively in the treatment of these solid tumors are overwhelmingly ineffective in the treatment of GBM, perhaps reflecting the eccentric biology and cellular origin of this neoplasm. To date, only one new agent has been documented to have modest activity against intermediate-grade gliomas, whereas no effective agents have emerged for the treatment of GBM, despite 20 years of enrolling patients in clinical trials. It is ironic that although a comprehensive view of the genetic lesions encountered in malignant gliomas has been compiled, substantive conceptual and practical barriers remain in assigning functional significance to these genetic changes and in harnessing this basic information into the development of drugs that make a difference in patient care.

The history of treating malignant gliomas dates back to the middle of the 19th century and parallels landmark advances in modern surgical technique and the clinical discipline of neurology. The first brain tumor surgery of the modern era was performed in 1884 by Rickman

${ }^{9}$ Corresponding author.

E-MAIL ron_depinho@dfci.harvard.edu; FAX (617) 632-6069.

Article and publication are at www.genesdev.org/cgi/doi/10.1101/ $\operatorname{gad} .891601$.
Godlee (Kaye and Laws 1995). By 1900, the initial enthusiasm for surgery had waned, because it became apparent that patients were not cured and that survival was only marginally prolonged. In efforts to improve surgical outcome, Harvey Cushing (1926), who had contributed major advances in surgical technique, pioneered the first histological grading scheme for gliomas and correlated it with clinical outcome (Kaye and Laws 1995). The grading scheme was based on the morphological resemblance of neoplastic cells to cell types found in the normal central nervous system (CNS). He and his colleague, Percival Bailey, described the seminal feature of gliomas, that is, their diffuse infiltrative nature, which renders them incurable by surgery alone. Radiation therapy was introduced soon thereafter in an attempt to cure these infiltrative tumors. Although clearly improving the median survival in intermediate-grade gliomas by many months and GBM by several months, the addition of radiation ultimately failed to alter long-term outcome (Bouchard and Pierce 1960). As chemotherapy was developed for leukemia and solid tumors, agents that could penetrate the blood-brain barrier were added to the treatment protocols of malignant gliomas. Nitrosurea-based chemotherapy, in combination with surgery and radiation therapy, emerged as the only regimen that improved median survival (Shapiro et al. 1989), predominantly in patients with intermediate-grade gliomas. Although nitrosureas have become standard therapy for malignant gliomas, it is now clear that patients are not cured with this or any other cytotoxic agent currently available, regardless of tumor grade.

As clinical investigators in neuro-oncology pursue novel therapies from the compendium of experimental agents available for clinical trials in cancer, the lack of glioma-targeted agents predicts a very limited chance of finding a successful therapy using this approach. Perhaps we can learn from Harvey Cushing, who sought an explanation for his inability to cure his patients despite the groundbreaking advances of his surgical techniques. Cushing undertook a complete reappraisal of the pathogenesis of GBM in the search for a reasonable explana- 
tion for his failures. What emerged was a new level of insight and understanding into the biology of these tumors that has persisted and underlies the current approach to treatment. With the advent of the molecular era, we now have the opportunity to reexamine the biology of these tumors with a level of precision that promises to make meaningful advances toward the development of specific and effective rational therapies.

This review describes the histopathologic and genetic lesions that characterize both the lower-grade and highly aggressive gliomas. These data will be integrated with the current state of knowledge of glial cell development because we are of the view that the combined insights of cancer genetics and developmental neurobiology will serve to illuminate the mechanisms driving gliomagenesis.

\section{Classification and grading of glioma}

Gliomas have been defined pathologically as tumors that display histological, immunohistochemical, and ultrastructural evidence of glial differentiation. The most widely used scheme for classification and grading of gliomas is that of the World Health Organization (WHO) (Kleihues and Cavenee 2000). Gliomas are classified according to their hypothesized line of differentiation, that is, whether they display features of astrocytic, oligodendroglial, or ependymal cells. They are then graded on a scale of I to IV according to their degree of malignancy as judged by various histological features (see below). Unlike other solid tumors, gliomas very rarely metastasize outside the CNS, and thus tumor grade is the primary determinant of clinical outcome. Grade I tumors are bio- logically benign and can be surgically cured if deemed resectable at the time of diagnosis; grade II tumors are low-grade malignancies that may follow long clinical courses but are not cureable by surgery; grade III tumors are malignant and lead to death within a few years; grade IV tumors are highly malignant, usually recalcitrant to chemotherapy, and lethal within 9-12 months. Seventy percent of grade II gliomas transform into grade III and IV tumors within 5-10 years of diagnosis and then behave clinically like the higher-grade tumors (Fig. 1).

The common gliomas that affect the cerebral hemispheres of adults are termed diffuse gliomas because of their propensity to infiltrate throughout the brain. This invasive nature is one of the cardinal features of malignant gliomas and results in the inability of surgery to cure patients even when these lesions arise in areas in which wide surgical resection is possible. Radiation therapy improves overall survival for each tumor grade, yet no patients are cured by this treatment modality. The diffuse gliomas are classified histologically as astrocytomas, oligodendrogliomas, or tumors with morphological features of both astrocytes and oligodendrocytes, termed oligoastrocytomas. Astrocytic tumors are subsequently graded as pilocytic astrocytoma, grade I; astrocytoma, grade II; anaplastic astrocytoma, grade III; and glioblastoma, grade IV. Oligodendrogliomas and oligoastrocytomas are subsequently graded as grade II or anaplastic, grade III. Such grading is related to the presence of histological features of malignancy, such as high cellularity, cellular pleomorphism, mitotic activity, microvascular proliferation, and necrosis. For instance, grade II astrocytomas have cellular pleomorphism but none of the other histological features listed above; grade
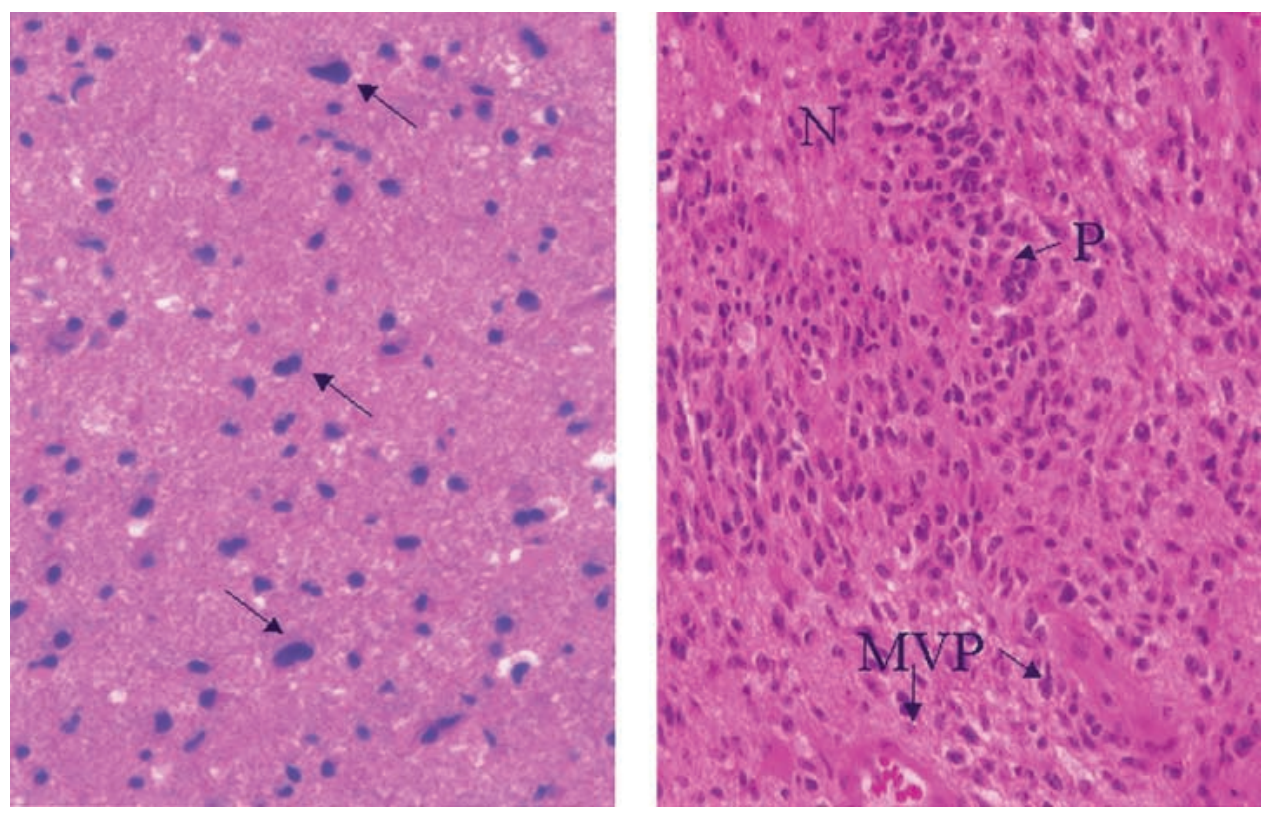

Figure 1. Two pathways to GBM. (Left panel) Astrocytoma, WHO grade II from a young woman whose tumor recurred 5 yr later as GBM (not shown). Note the mild increase in cellularity, with scattered neoplastic astrocytes having elongated hyperchromatic nuclei (arrows). (Right panel) GBM in an elderly man with a short clinical history. Note the dense cellularity, necrosis (N) with palisading nuclei $(\mathrm{P})$ and microvascular proliferation (MVP) — the histological hallmarks of GBM. 
III anaplastic astrocytomas also display mitotic activity. and grade IV glioblastomas exhibit microvascular proliferation and/or necrosis. As we move forward, it is anticipated that histopathologic diagnosis will be joined by molecular-profiling technology (Huang et al. 2000) in assigning gliomas to particular categories and therapeutic groups (see below).

\section{Cellular origins of glioma}

To understand the pathophysiology of the gliomas, we must look at the important questions raised by the histological features and clinical presentation that may guide investigation and therapeutic development in this area. These questions include the following: (1) Why are the cells so invasive, even when low grade, and what are the properties of the microenvironment that permit widespread invasion? (2) Why do low-grade tumors transform into high-grade tumors after a long latency, and what genetic pathways govern this transformation? (3) What are the mechanisms underlying the pathological features of high-grade tumors, including increased mitotic rate and induction of neovascularization? (4) What are the molecular causes of resistance to therapy in the high-grade tumors?

\section{GBM: two roads-one clinical entity}

An important clue to pathways involved in gliomagenesis may lie in the two GBM subtypes that have been identified clinically (Fig. 2; Kleihues and Cavenee 2000). Primary GBM typically presents in older patients as an aggressive, highly invasive tumor, usually without any evidence of prior clinical disease. Secondary GBM has a very different clinical history. It is usually observed in younger patients who initially present with a low-grade astrocytoma that transforms into GBM within 5-10 years of the initial diagnosis, regardless of prior therapy. The cataloging of genetic lesions in these GBM subtypes has identified differences in their genetic profiles, predominantly in the penetrance of specific genetic mutations. As a result, it has been proposed that primary and secondary GBM represent two distinct clinical entities, each developing along distinct genetic pathways (Kleihues and Cavenee 2000). However, the distinctions become blurred when one considers the striking clinical, genetic, and biologic similarities between these two subtypes. First, primary and secondary GBMs behave in a clinically indistinguishable fashion. The median survival from the time that GBM is established does not statistically differ between these two subtypes, reflecting equivalent rates of proliferation and invasion as well as resistance to all therapeutic modalities. Second, although the frequency of specific genetic mutations may differ between the subtypes, the same genetic pathways appear to be targeted in both GBM subtypes. Third, once established, primary and secondary GBM are indistinguishable to the neuropathologist. Both show microvascular proliferation and pseudopalisading necrosis, and both are composed of highly infiltrative, less well-differentiated cells than are low-grade astrocytomas. It has been postulated that in secondary GBM, malignant astrocytes in low-grade gliomas undergo dedifferentiation during progression to GBM, possibly because of the accumulation of genetic mutations in key pathways regulating glial cell differentiation. It can be argued that a similar mechanism may be operative in primary GBM, although an alternate thesis poses that primary GBMs represent malignant transformation of the more primitive glial precursor cells, such as the pluripotent neural stem cell or a committed glial progenitor. In fact, it would not be unreasonable to speculate that the state of glial cell differentiation may modulate the biological effects of a given mutation or combination of mutations, leading to the varied clinical presentation and progression courses in these two GBM subtypes. For example, an immature state of differentiation may be permissive for the transforming effects of a cancer-relevant mutation, although it is also possible that a genetic mutation

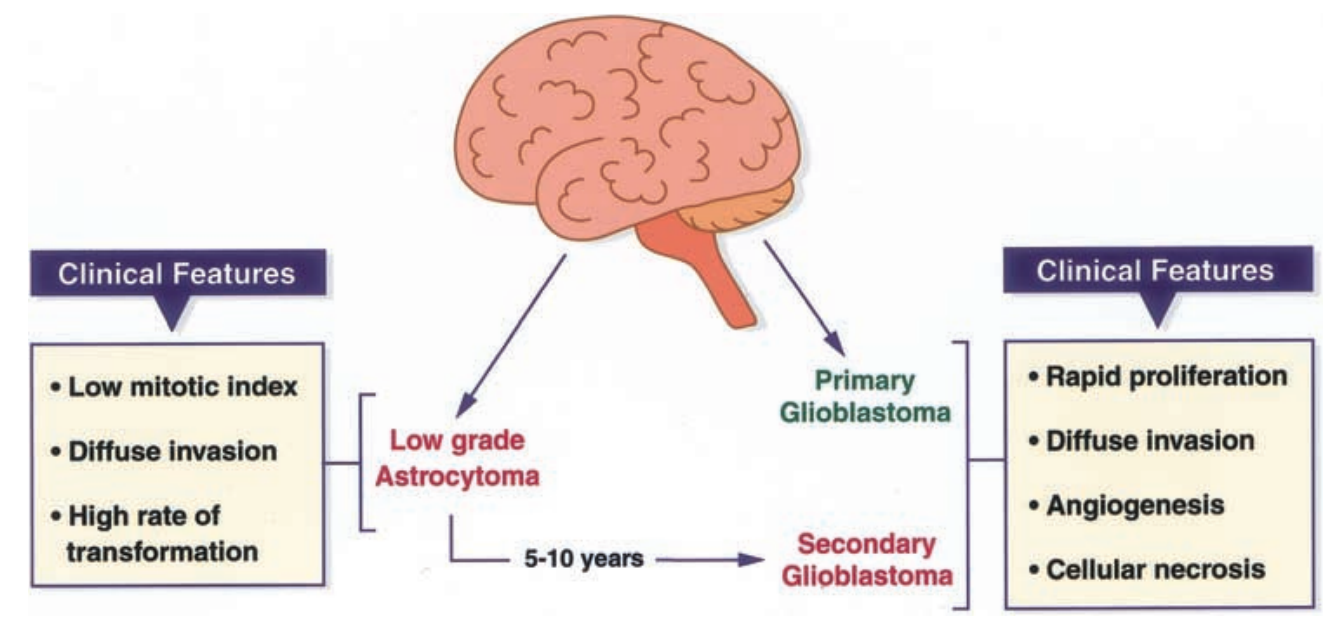

Figure 2. Two pathways to GBM. GBM can develop over 5-10 yr from a low-grade astrocytoma (secondary GBM), or it can be the initial pathology at diagnosis (primary GBM). The clinical features of GBM are the same regardless of clinical route. 
may alter the state of differentiation in the transforming process. Thus, to truly dissect the molecular pathways underlying GBM and to assign clinical and biological relevance to the variance in penetrance of specific genetic mutations in primary and secondary GBM, we must explore the issue of cell-of-origin in this neoplasm.

\section{Glioma variants: clues to the cell-of-origin}

A clue to glioma histiogenesis may lie in the existence of the well-described glioma variants, mixed oligoastrocytomas and gliosarcomas. The histological hallmarks of these tumors are a biphasic tissue pattern with areas of astrocytic and oligodendroglial differentiation or gliomatous and mesenchymal differentiation, respectively (Kleihues and Cavenee 2000). The presence of two morphologically distinct cell types within a tumor suggests either independent transformation events in two terminally differentiated cells or, more likely, the malignant transformation of a progenitor cell that retains the capacity to differentiate into both cell types. An analysis of the genetic profile of the individual cell types within the tumor would be most informative in distinguishing between these two possibilities. If malignant transformation occurs in the progenitor cell, one would expect a similar genetic profile, especially on the level of chromosomal changes, in both cell types. Indeed, in mixed oligoastrocytomas, loss of heterozygosity $(\mathrm{LOH})$ of $1 \mathrm{p}$ and $19 \mathrm{q}$ was observed in areas of both oligodendroglial and astrocytic differentiation, strongly suggesting that both oligodendroglial and astrocytic cells were derived from a single precursor cell (Kraus et al. 1995). Similarly, in gliosarcoma, genetic analysis of the microdissected glial and sarcomatous elements, using single-strand conformation analysis and direct DNA sequencing of the p53 gene, revealed that both cell types carried identical mutations (Biernat et al. 1995; Mueller et al. 2001). These findings suggest that the glial and sarcomatous cells clonally evolved from either a multipotent neural stem cell or an early glial progenitor that retains the ability to differentiate into a muscle phenotype. A similar phenomenon was reported in recent cell culture studies of rodent embryonic cortical neural stem cells (Mujtaba et al. 1998; Tsai and McKay 2000). Under defined culture conditions, single isolated clones of stem cells exhibited the capacity to differentiate into both GFAPexpressing astrocytes and smooth muscle cells. These observations are reminiscent of the widely described tendency of glioma cells to eventually lose glial and gain mesenchymal features with passage in culture (McKeever et al. 1991).

The development of a smooth muscle cell from a neural stem cell is particularly noteworthy in light of their distinct germ cell origins, that is, CNS develops from ectoderm whereas muscle derives from mesoderm. Indeed, mounting experimental evidence has established that neural stem cells retain a much broader differentiation potential than previously thought. Cultured multipotent neural stem cells and oligodendrocyte progenitors have been shown to give rise to myeloid cells when transplanted into irradiated mice (Bjornson et al. 1999), to skeletal muscle when transplanted into regenerating muscle (Galli et al. 2000), or to cell-type derivatives of all three germ layers when microinjected into blastocysts (Clarke et al. 2000).

\section{Neural stem cells in the adult brain}

The identification, within the adult CNS, of neural stem cells (Reynolds and Weiss 1992; Palmer et al. 1997; Roy et al. 1999) endowed with the capacity for self-renewal and differentiation into mature astrocytes and neurons in response to injury (Johansson et al. 1999) revealed a level of plasticity in the adult brain that was previously unrecognized. The finding lends support to the hypothesis that neural stem cells or early glial progenitors could be the targets of transformation in gliomagenesis. Although these cells are localized to areas of the brain that are not common sites of glioma development, predominantly the subventricular zone (Reynolds and Weiss 1992) and the dentate gyrus of the hippocampus (Palmer et al. 1997; Roy et al. 1999), the proliferative and migratory capabilities of these cells predict that tumor formation could occur anywhere in the brain. Indeed, it is conceivable that a tumor-associated mutation may activate the migratory nature of the stem cell sending this initiated cell out of the subventricular zone into the striatum, septum, or cortex, as is seen in embryogenesis and in response to exogenous epidermal growth factor in adult mice (Craig et al. 1996; Fricker-Gates et al. 2000). This premalignant cell, which is now in an aberrant location, could go on to acquire additional genetic mutations leading to a fully transformed cell.

\section{Dedifferentiation: is astrocyte differentiation a terminal event?}

Another possible source of transformed glia with stem cell-like properties is the mature astrocyte or oligodendrocyte that may be induced to dedifferentiate in response to a genetic mutation. The existence of cells in the adult brain that are capable of dedifferentiation in response to certain stimuli lends support to the hypothesis that mature cells may be the targets in gliomagenesis. For us to better understand this possible route to transformation, it is worth considering certain aspects of CNS development.

The radial glia are among the first cells to appear in the developing CNS (Fig. 3), having a critical role in neural and glial development and in overall laminar organization of the neocortex (Rakic 1972). They proliferate and establish lattice-like scaffolding, which act as guides for neuronal and glial progenitors as they migrate out of the ventricular zone into the developing cortex (Hatten 1990). The differentiation of radial glia into astrocytes takes place once all neuronal and glial cells have migrated out of the subventricular zone (Voigt 1989). Although this process was previously thought to be a terminal event, recent studies of explanted embryonic cor- 


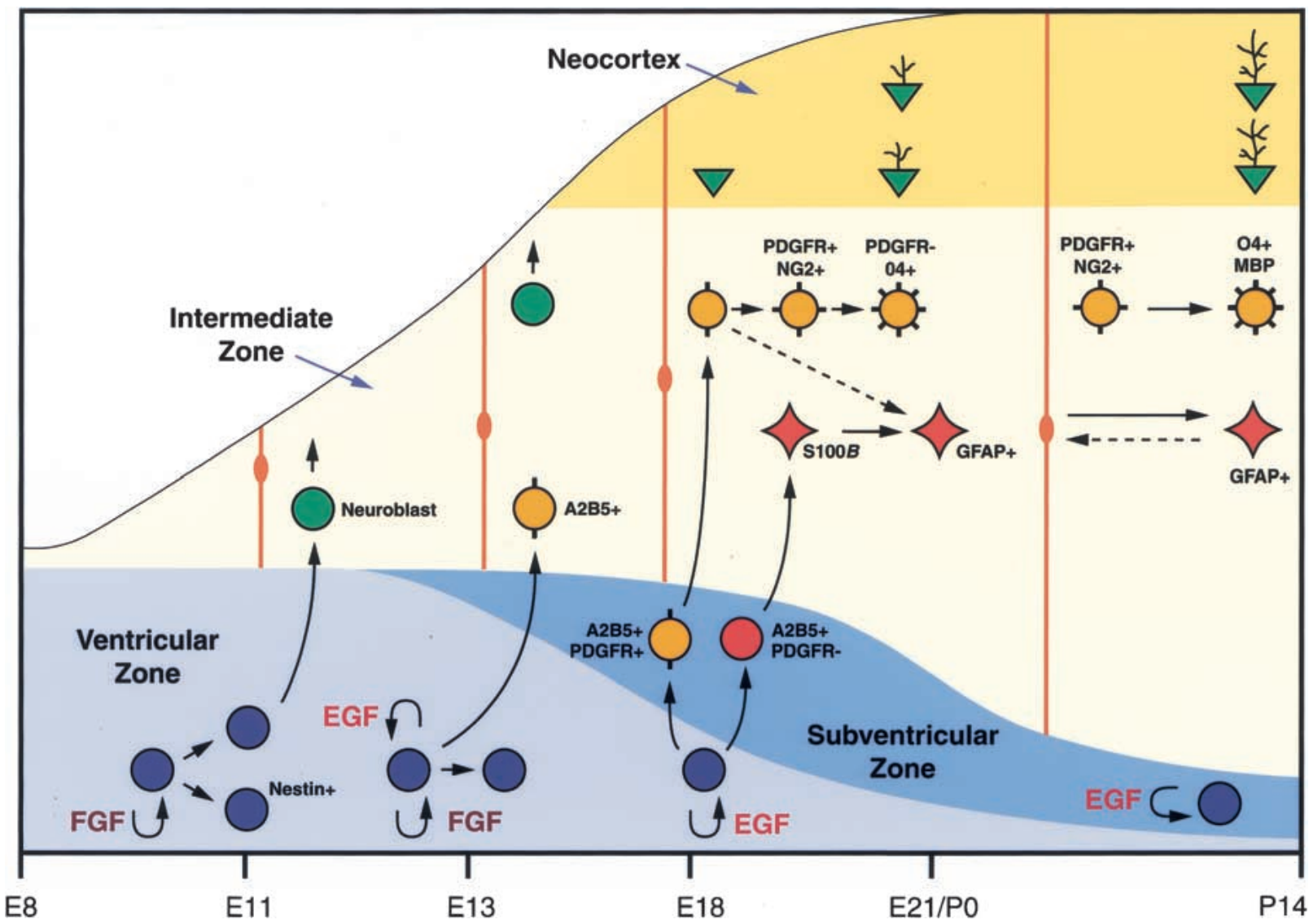

Figure 3. Embryonic and perinatal development of glial cells. X-axis represents days in embryonic development. Y-axis represents developing brain layers. Although represented as a continuum, each embryonic day represents a cross-section of cellular architecture. By embryonic day 8 (E8) pluripotent stem cells of the ventricular zone (blue filled circles, nestin+) driven by fibroblast growth factor (FGF) first produce radial glial cells (orange elongated cells) in the intermediate zone. The radial glia proliferate and establish latticelike scaffolding, which act as guides for neuronal and glial progenitors as they migrate out of the ventricular zone. By E13, the pluripotent stem cells become progressively more EGF responsive and give rise to glial restricted progenitor, A2B5+ (shown in yellow), as well as continue to self-renew under the influence of EGF. The neuroblasts (green) continue to migrate via the radial glia into the neocortex where they undergo neuronal differentiation (green triangles). By E18, the stem cells in the ventricular zone are responsive only to EGF and produce the glial restricted progenitors, A2B5+, PDGFR+ (shown in yellow) and A2B5+, PDGFR- (shown in red) which also migrate from the ventricular zone into the intermediate zone where they undergo differentiation into the oligodendroglial lineage cells (shown in yellow) or astrocyte lineage (shown in red), respectively, eventually differentiating into the mature oligodendrocyte $(\mathrm{O} 4+\mathrm{MBP})$ and astrocyte $(\mathrm{GFAP}+)$. In vitro studies have shown that oligodendrocyte progenitors can differentiate into astrocytes (dashed arrow, E18-E21). Also, astrocytes both in vivo and in vitro may dedifferentiate into radial glial (dashed arrow, P14).

tical tissue have shown that mature astrocytes in the recipient brain are able to dedifferentiate into an earlier radial glia-like phenotype, even those astrocytes that are found at considerable distances from the site of implantation (Hunter and Hatten 1995; Soriano et al. 1997). This action at a distance illustrates that explant-derived factors are capable of diffusing across long distances and that mature astrocytes retain the ability to respond to these factors. This dedifferentiation process can be triggered in vitro by the addition of conditioned media from embryonic brain explants (Hunter and Hatten 1995). Furthermore, it has been demonstrated that a highly selective nontraumatic phototoxic lesion of a limited number of neurons in the adult mouse cortex leads to dedifferentiation of astrocytes into radial glia in the surrounding vicinity (Leavitt et al. 1999; Magavi et al. 2000). These observations raise the intriguing possibility that astrocytes in the adult brain can dedifferentiate into radial glia and acquire the full complement of proliferative and migratory capabilities that these important progenitor cells possess in early CNS development. Thus, in gliomagenesis, genetic mutations may serve to convert astrocytes into a more immature state in which it normally proliferates and migrates-capabilities reminiscent of the key biological properties of astrocytomas.

\section{Common biological and molecular themes} in the development of normal and neoplastic glia

The prominence of mutations in components of the cell cycle as well as the apoptotic pathway in gliomas with 
the attendant dysregulation of growth, survival, and migration suggests that these targets are likely to be important in glial development. What follows is a discussion of the various components of these pathways in gliomagenesis (Table 1) and gliogenesis when known.

\section{The glioma-relevant pathways}

Growth factor pathways: PDGF and EGF Platelet-derived growth factor (PDGF) and epidermal growth factor (EGF) are thought to have important roles in gliogenesis: EGF in neural stem cell proliferation and survival, PDGF in glial development. The prominent overexpression of PDGF in low-grade gliomas and EGF receptor (EGFR) in GBMs suggests that these receptor tyrosine kinase (RTK) signaling pathways are critical targets in gliomagenesis. RTKs signal through several effector arms, including Ras/MAPK (MAP kinase), PI3-K (phosphoinositide $\underline{3}$-kinase), PLC- $\gamma$ (Phospholipase $\underline{\mathrm{C}}$ ), and JAK-STAT (- $\underline{\text { signal }}$ transducers and activators of transcription), which regulate cellular proliferation, cell scatter and migration, and cytokine stimulation (for review, see Heldin 1996). Given the scope of biological effects from RTK stimulation, it is reasonable to anticipate that a detailed understanding of RTK function in normal brain development will aid in the investigation of how their dysregulation drives malignant transformation and/or progression.
PDGF-PDGFR PDGF is thought to be a critical regulator of gliogenesis, with predominant effect on oligodendrocyte development. During embryogenesis, neurons and astrocytes express PDGF (Yeh et al. 1991), whereas glial progenitors and neurons express the PDGF-receptor (R)- $\alpha$ (Yeh et al. 1993). During the postnatal period, as glial progenitors differentiate into oligodendrocytes, PDGF-R- $\alpha$ expression is down-regulated. Accordingly, mice lacking the PDGF homodimer (PDGF-AA) have a dramatic reduction in the number of glial progenitors and oligodendrocytes when compared with normal mice (Calver et al. 1998). Conversely, neuron-specific enolasedirected overexpression of PDGF-AA results in a marked increase in the number of glial progenitors that, upon differentiation, generate an excess of abnormally localized oligodendrocytes that subsequently undergo apoptosis before birth (Calver et al. 1998). In the adult brain, PDGF-R- $\alpha$ expression is restricted to the ventricular and subventricular zone of the lateral ventricles, possibly restricted to neural stem cells, whereas PDGF is widely expressed by neurons and astrocytes (Oumesmar et al. 1997). In the subventricular zone of the lateral ventricle, PDGF-R- $\alpha$, in addition to other proposed molecules (Gates et al. 1995), may play a role in the normal differentiation and migration of neural stem cells into neurons as they migrate to the olfactory bulb (Louis 1994). Curiously, PDGF-R- $\alpha$ positive cells, which morphologically and immunohistochemically resemble glial pro-

Table 1. Relationship between median survival, histological features, and major genetic lesions associated with each tumor

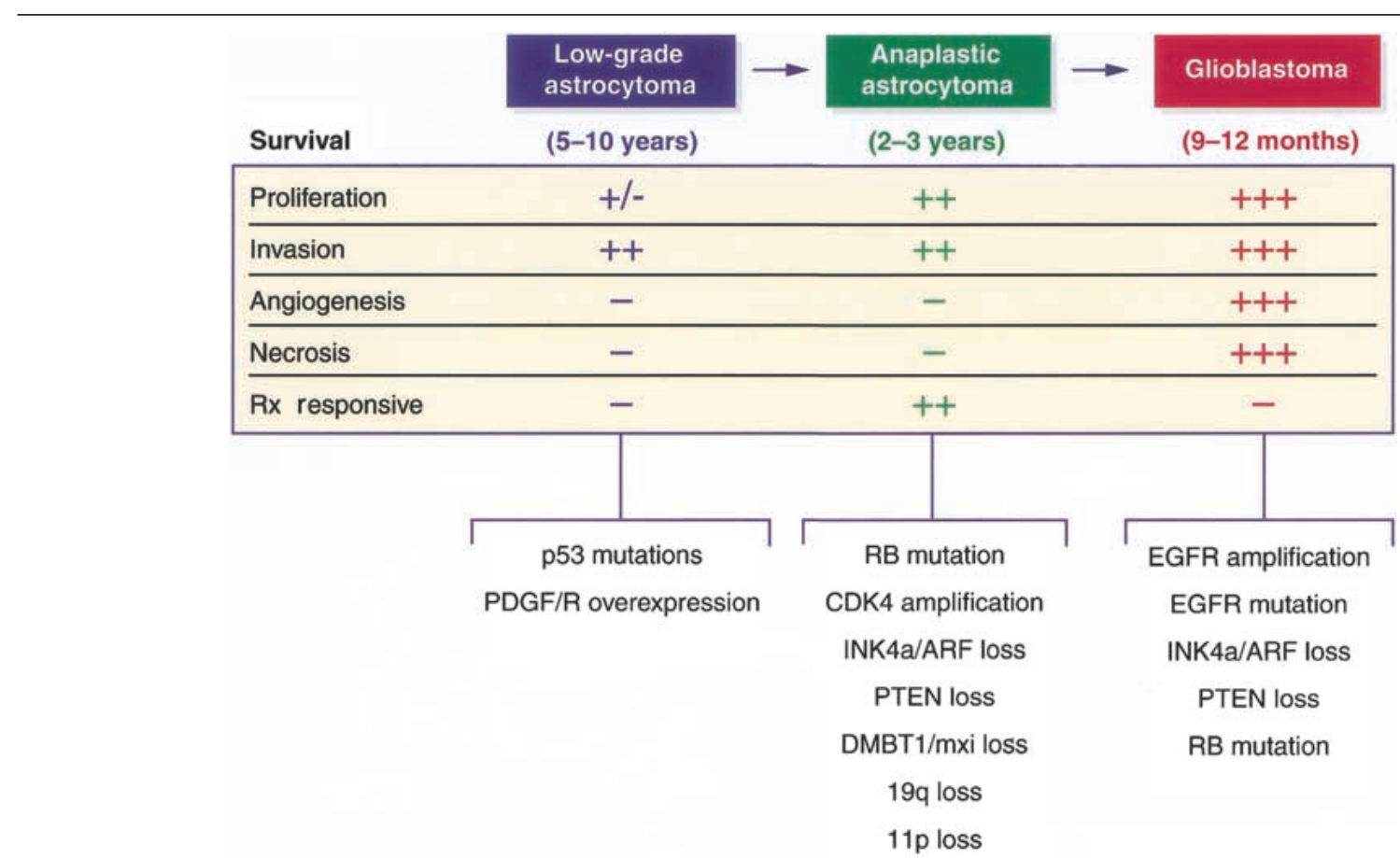

Relationship between median survival, histological features and major genetic lesions associated with each tumor. Note that the genetic lesions listed here as associated with glioblastoma are the same for primary and secondary GBM, although the penetrance of the various lesions differs between the two subtypes. 
genitors, are found scattered throughout the white matter and cerebral cortex of rodents (Pringle et al. 1992) and humans (Roy et al. 1999; Scolding et al. 1999). A subpopulation of these cells coexpress NG2 (an integral membrane chondroitin sulfate proteoglycan) and undergo proliferation in response to a variety of stimuli such as demyelination and inflammation, suggesting that they are dynamic cells capable of responding to changes in the environment (Fidler et al. 1999; Zhang et al. 1999). A recent study has identified these NG2/ PDGF-R- $\alpha$ positive cells in oligodendrogliomas (Shoshan et al. 1999|, raising the possibility that these cells may be precursors of some oligodendrogliomas.

Analysis of low-grade astrocytomas has identified two common events: PDGF ligand and receptor overexpression (Heldin and Westermark 1990; Claesson-Welsh 1994) and p53 loss-of-function mutations (Chung et al. 1991; von Deimling et al. 1992a). Although rare astrocytomas have amplification of the PDGF-R- $\alpha$ receptor gene (Hermanson et al. 1996), the actual mechanisms leading to PDGF overexpression in most cases have not been elucidated. Tumors often overexpress both PDGF ligands and receptors, suggesting the establishment of an autocrine stimulatory loop (Hermanson et al. 1992). The pattern of robust expression of PDGF ligands and receptors in low-grade gliomas tracks closely with p53 mutations (Hermanson et al. 1996), thus pointing to important genetic interactions between PDGF and p53.

The proliferative stimulus provided by PDGF signaling is capable of promoting reentry into the cell cycle, a stimulus known to elicit a p53-mediated apoptotic response. Thus, one may be tempted to speculate that mutational inactivation of p53 in the setting of PDGF overexpression serves to promote the survival of aberrantly cycling premalignant cells. However, overexpression of this potent growth factor is associated with a very low proliferative rate in low-grade gliomas in vivo. There are several possible explanations for this apparently contradictory finding. First, perhaps the action of PDGF is incomplete, somehow opposed by inhibitors operating on the level of the core cell-cycle machinery (see below). Second, although PDGF stimulation of the Ras/MAPK signaling pathway up-regulates D-type cyclins (Weber et al. 1997), this focal effect may be insufficient to stimulate robust cell-cycle entry in glioma cells. Third, because PDGF engages several pathways in addition to Ras, it is possible that signaling through one or multiple PI3$\mathrm{K}$, JAK-STAT or PLC- $\gamma$ pathways is more prominent than is signaling through Ras. In fact, the different dimeric forms of the related PDGF receptors may differentially activate the various components of the RTK cascade, leading to differential effector responses. Perhaps PDGF's most important role in the low-grade tumors may be to induce tumor cell migration through activation of PI3-K and PLC- $\gamma$, both of which have been implicated in migration and scattering (Heldin 1996; Willis et al. 2000). Although PDGF's role in smooth muscle cell, fibroblast, and oligodendrocyte migration is well established (Wolswijk et al. 1991; Bilato et al. 1995; Milner et al. 1997; Facchiano et al. 2000), its role in modulating astrocyte migration is less well defined and therefore merits further investigation. Indeed, cell culture studies have revealed the capacity of PDGF to stimulate migration of oligodendrocyte progenitor cells (Simpson and Armstrong 1999|, neonatal rat cortical astrocytes (Bressler et al. 1985), and embryonic rat neural stem cells (Forsberg-Nilsson et al. 1998). In cell culture-based studies, PDGF, in combination with bFGF, has been shown to promote proliferation of glial progenitors and inhibit their terminal differentiation (McKinnon et al. 1990).

EGF-EGFR The majority of gene amplification events in high-grade astrocytomas involves EGFR (Libermann et al. 1985; Wong et al. 1987; Bigner et al. 1990), being amplified in $\sim 50 \%$ of GBMs and a few anaplastic astrocytomas (Wong et al. 1987). The low frequency of amplification seen in anaplastic astrocytomas suggests that EGFR activation may be responsible for driving the transformation process toward GBM. In attempting to ascribe biological function to EGFR amplification, researchers currently are attempting to address whether it represents the critical pathway mediating neovascularization, the marked increase in proliferation and resistance to cell death that characterizes GBM. Here again, a review of the role of the EGFR pathway in normal development may prove instructive.

Peak EGFR expression coincides with the peak of gliogenesis in the embryonic and early perinatal period (Burrows et al. 1997), suggesting a critical role in astrocyte and/or oligodendrocyte development. Indeed, spontaneous mutant mouse strains waved 1 and waved 2, now known to harbor the mutant TGF- $\alpha$ and hypomorphic EGFR allele, respectively (Luetteke et al. 1993, 1994), show decreased numbers of astrocytes and a smaller subventricular zone compared with those of the normal adult brain (Weickert and Blum 1995). However, targeted deletion of EGFR in mice results in embryonic or perinatal lethality, and the mice demonstrate cortical dysgenesis, neuronal ectopias, and reduced numbers of astrocytes (Miettinen et al. 1995; Threadgill et al. 1995; Sibilia et al. 1998), suggesting that EGFR plays a more complex role in CNS development. This is supported by several lines of evidence. First, retroviral-mediated overexpression of EGFR in the early ventricular zone results in proliferation of stem cells as well as premature astrocytic differentiation (Burrows et al. 1997). Second, EGFresponsive stem cells of the ventricular zone/subventricular zone retain the capacity to generate all three major cell types in vitro (Reynolds and Weiss 1996). Third, cultured neural stem cells, upon transplantation into the adult brain, preferentially differentiate into astrocytes (Fricker-Gates et al. 2000). However, if EGF is simultaneously infused into the lateral ventricles, then the transplanted neural stem cells remain undifferentiated and continue to proliferate (Fricker-Gates et al. 2000). Finally, Zhu et al. (1999) demonstrated that a specific EGFR inhibitor that blocked EGF-induced stem cell proliferation did not affect bone morphogenic protein (BMP)-induced or ciliary neurotrophic factor (CNTF)induced astrocyte differentiation, suggesting that the in- 
creased bias to astrocyte differentiation in late embryonic period is independent of EGF signaling. Taken together, although EGFR may have a role in astrocyte differentiation, the signaling pathway appears to be necessary for sustained proliferation and perhaps survival of the neural stem cell compartment. This is particularly interesting in regards to the overexpression of EGFR in GBM and perhaps provides an important clue to the role of EGFR overexpression in malignant glial cells.

There is evidence that GBMs express the endogenous ligands, EGF and TGF- $\alpha$ (Ekstrand et al. 1991) in addition to EGFR, which is consistent with the existence of an autocrine growth stimulatory loop. Mechanistically, EGFR-driven mitogenesis appears to encompass liganddriven dimerization of receptor monomers; tyrosine kinase activation; tyrosine phosphorylation of the receptor; signaling through various coupling and adaptor proteins, such as Shc and Grb2, to signal transduction pathways driven by PLC- $\gamma$, Ras/MAPK, or STAT; and finally, receptor-ligand internalization and lysosomal breakdown, leading to signal attenuation (Yarden and Schlessinger 1987). In malignant gliomas, specific mutations affecting Ras have not been detected. However, high levels of Ras-GTP have been documented in highgrade astrocytomas in one study (Guha et al. 1997), suggesting that the Ras effector arm may be activated by upstream events, such as RTK activation.

Approximately $40 \%$ of the GBMs with EGFR amplification also commonly express a variant form called EGFRvIII, $\triangle$ EGFR, or del2-7EGFR (herein referred to as activated EGFR). This mutant lacks a portion of the extracellular ligand-binding domain as the result of genomic deletions that precisely eliminate exons 2-7 in the EGFR mRNA (Humphrey et al. 1990; Wong et al. 1992) and is constitutively autophosphorylated, albeit at a significantly lower level than is seen in ligand-driven wildtype EGFR phosphorylation (Ekstrand et al. 1991; Nishikawa et al. 1994). Unlike wild-type EGFR, the constitutively active mutants are not down-regulated, suggesting that their altered conformation does not result in exposure of receptor sequence motifs required for endocytosis, lysosomal degradation, and signal attenuation. The introduction of this truncated receptor into glioma cells dramatically enhances their tumorigenicity in vivo (Nishikawa et al. 1994) through both increased cellular proliferation and reduced apoptosis (Nagane et al. 1996). In addition, it confers resistance to chemotherapeutic drugs such as cisplatin through modulation of Bcl- $\mathrm{X}_{\mathrm{L}}$ expression and consequent inhibition of induction of apoptosis by the drug treatment (Nagane et al. 1998). EGFR autocrine signaling induces cell scattering and migration in glioma cells in vitro (El-Obeid et al. 1997), and glioma cells expressing mutant EGFR show enhanced invasiveness when implanted in the mouse brain and compared with control cells (Mishima et al. 1999).

The p53 Pathway Allelic loss of chromosome 17p and p53 mutations are observed with equal frequency in lowgrade gliomas, anaplastic astrocytomas, and secondary glioblastomas (Louis 1994), suggesting that inactivation of $p 53$ is an early event in gliomagenesis. In human gliomas, p53 mutations are primarily missense mutations and target the evolutionarily conserved domains in exons 5,7 , and 8 , thus affecting residues that are crucial to DNA binding (Louis and Cavanee 1997). The observation that gliomas are part of the tumor spectrum seen in patients with Li-Fraumeni syndrome (Malkin et al. 1990) serves to solidify a causal role for p53 inactivation in gliomagenesis. Because brain radiation during childhood is the only definitive risk factor for the development of gliomas (Ron et al. 1988; Neglia et al. 1991), it is possible that this link could reflect deactivation of the p53-dependent DNA damage checkpoint response so as to permit cell survival following radiation exposure. Although p53 status has been examined in several high-grade gliomas following radiation (Brat et al. 1999), an examination of p53 mutations has not been conducted in lowgrade astrocytomas.

The characteristically low mitotic rate and high rate of further transformation seen in low-grade gliomas may reflect direct consequences of p53 inactivation. Perhaps the genomic instability associated with p53 loss facilitates the accumulation of additional genetic mutations that promote the transformation to secondary GBMs. However, the 5-10 year latency for this transition suggests that p53-related genomic instability may not be the primary genetic defect driving this lethal transition. At the very least, p53 deficiency appears to play a permissive role, as suggested by the clonal outgrowth of subpopulations of low-grade glioma cells seen in high-grade astrocytomas with homogeneous p53 mutations (Sidransky et al. 1992).

Perhaps the most important modulator of p53 is one of its downstream gene targets, MDM2, a gene located in the 12q14.3-q15 chromosomal region encoding a $54-\mathrm{kD}$ protein (Mitchell et al. 1995). MDM2 inhibits p53 transcriptional activity directly by binding to the N-terminal transactivation domain and also functions as an E3 ubiquitin ligase, serving a critical role in the ubiquitination and proteosomal degradation of p53 (Momand et al. 1992; Haupt et al. 1997; Kubbutat et al. 1997). Transcription of the MDM2 gene is induced by p53 (Barak et al. 1994; Zauberman et al. 1995), creating a negative feedback loop that regulates the activity of the p53 protein and expression of MDM2 (Picksley and Lane 1993).

p53 engages a network of genes that could conceivably participate in the transformation process, particularly in tumors in which p53 remains wild type. Yet curiously, mutations in known downstream targets, such as p21 and BAX, have not been documented in gliomas, although a more extensive genome-wide survey of the p53 transcriptome has not been performed. Lack of these downstream mutations may relate to the need to impact on p53 itself, given its keystone role in processes of transformation. Alternatively, dysregulation of the p53 pathway may occur more commonly on the level of posttranslational regulation, impacting on p53 stability and activity. Along these lines, however, an analysis of gliomas with intact p53 has revealed an absence of MDM2 amplification or overexpression in low-grade gliomas 
(Reifenberger et al. 1993) and only a low frequency of amplifications in anaplastic astrocytomas and GBMs. The recent observation of epigenetic silencing of Apaf-1 in melanomas with intact p53 (Soengas et al. 1999) as well as the ability of MDMX to regulate p53 activity in cancer cells (Jackson and Berberich 2000) should expand the search for additional genetic lesions along the p53 pathway in malignant gliomas and the way such alterations influence tumor biology and therapeutic responses.

The RB pathway (RB, CDK4/6, and INK4a) The transformation from low- to intermediate-grade gliomas (anaplastic astrocytomas) is characterized primarily by a dramatic increase in mitotic rate without induction of neovascularization. The transition is accompanied by allelic losses on chromosomes $9 \mathrm{p}$ and $13 \mathrm{q}$, and less frequently, by $12 \mathrm{q}$ amplification. Notably, these mutations are mutually exclusive events (Schmidt et al. 1994; Ueki et al. 1996) and are now known to be key components of the RB pathway (Fig. 4).

The retinoblastoma gene $(R B 1)$ maps to chromosome $13 \mathrm{q} 14$ and encodes the $107-\mathrm{kD}$ retinoblastoma protein $(\mathrm{pRB})$, a major regulator of cell-cycle progression. In the quiescent cell, $\mathrm{pRB}$ is in its hypophosphorylated state bound to E2F, preventing transcription of genes important for mitosis and thus preventing progression through the G1/S restriction point (for review, see Sherr 1996). Mitogen-induced Ras/MAPK signaling promotes cyclin D1 transcription, which subsequently complexes with cyclin-dependent kinases (CDKs) 4 and 6 initiating the phosphorylation of $\mathrm{pRB}$. Phosphorylation is completed by cyclin E/CDK2, causing release of pRB from E2F, activation of E2F-responsive genes, and subsequent entry into $S$ phase. Negative regulation of the CDKs is accomplished by the CDK inhibitors (CKIs), one family of which inhibits the G1 CDK4 and CDK6, and a second CKI family that acts as a more general inhibitor of CDKs including CDK2. Unscheduled cell-cycle entry can result from mutational inactivation of $\mathrm{RB}$ itself or the CKIs, epigenetic down-regulation of CKI levels, or amplification/overexpression of CDK4 or 6 or the D-type cyclins (for review, see Sherr 1996). Germline mutations in $R B$ are associated with retinoblastoma, the most common pediatric intraocular tumor, arising after transformation of an immature progenitor cell in the inner retinal neuroepithelium (Gonzalez-Fernandez et al. 1992). Expectedly, $R B$ mutations have been described $\sim 25 \%$ of high-grade astrocytomas (James et al. 1988; Henson et al. 1994).

$\mathrm{pRB}$ has been implicated in cellular differentiation (refs), although a direct role for RB in normal gliogenesis has not been identified. Recent data, however, have pointed to a key component in the RB pathway, the CKI

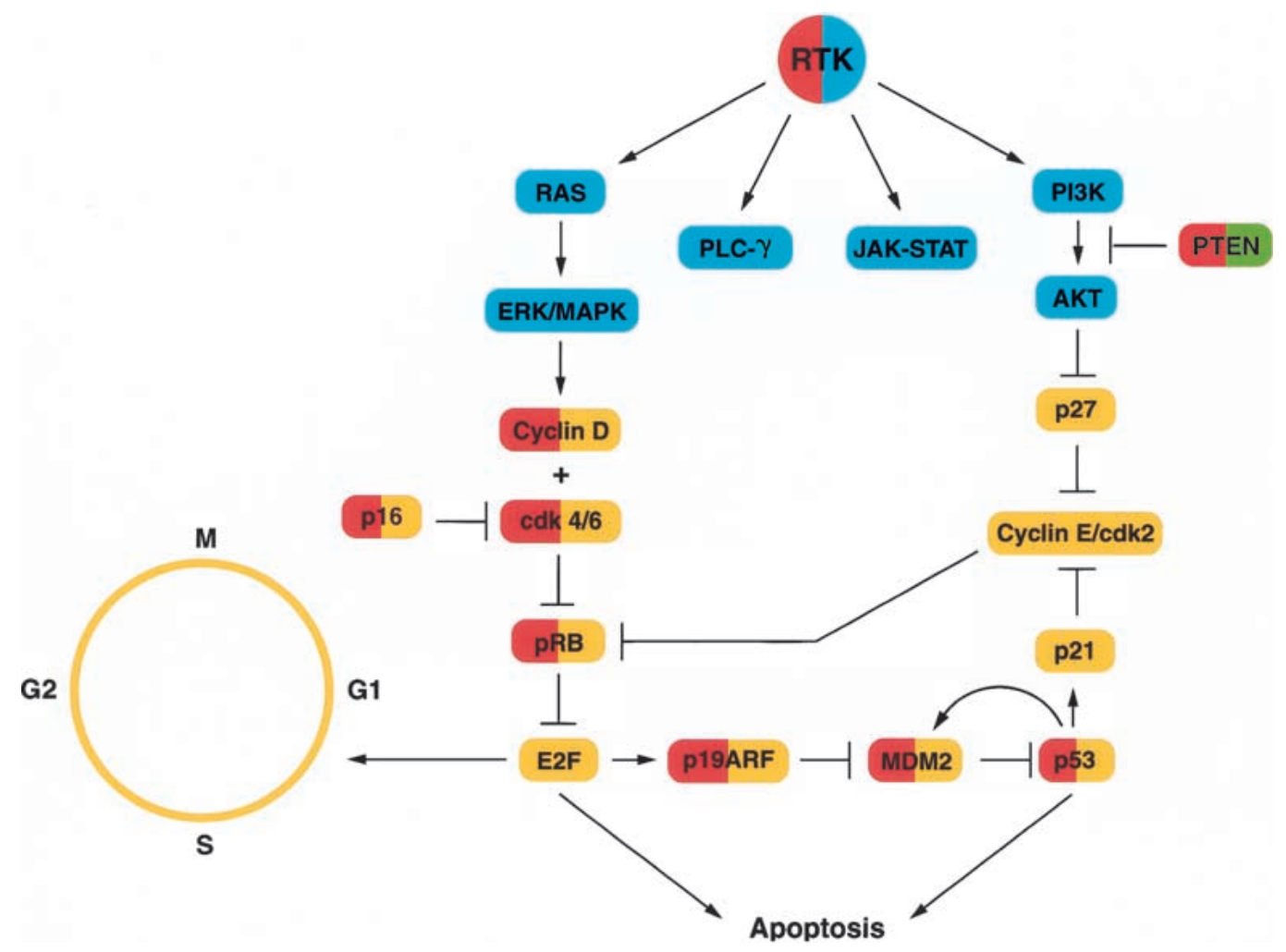

Figure 4. Integration between RTK pathways and the cell cycle. RTK, activated in gliomas by PDGF or EGFR, can signal through Ras-ERK/MAPK, PLC $\gamma$, JAK-STAT, and PI3-K pathways. Shown here, Ras and PI3-K engage the cell-cycle machinery at different levels. (Blue) RTK pathways, (yellow) cell-cycle components, (green) PTEN pathway, (red) components of RTK, cell cycle, or PTEN pathway mutated in malignant gliomas. 
p27Kip1 (hereafter referred to as p27), in the timing mechanism governing progenitor cell commitment. p27 regulates progression from $\mathrm{G} 1$ to $\mathrm{S}$ phase by directly inhibiting cyclin E-dependent kinases and indirectly inhibiting cyclin D-dependent kinases (Sherr 2000). In three different neuronal cell types-the oligodendrocyte progenitor O2-A (Durand et al. 1998), retinal progenitors (Levine et al. 2000), and granule cells of the cerebellum (Migheli et al. 1999; Miyazawa et al. 2000)—p27 levels have been shown to increase progressively as these cells proliferate in culture. Progressive accumulation of p27 to a critical threshold coincides with cell-cycle arrest and onset of differentiation. Consistent with a prominent role for p27 in these processes are findings that overexpression of p27 can inhibit proliferation of the progenitors, whereas loss of p27 function allows for an increase in the number of glial progenitor cell divisions (Tikoo et al. 1998). These patterns are highly analogous to the hematopoietic system, in which p27 deficiency has been shown to increase the proliferation of the progenitor pool while having no discernible impact on the pluripotent stem cell compartment (Cheng et al. 2000). Although cancer-associated p27 mutations have not been reported, GBM cell lines and glial tumors exhibit an inverse correlation between the levels of p27 protein and the proliferative (Ki-67) index and mortality rates (Fuse et al. 2000). Although it is reasonable to assume that p27 is executing these actions through its regulation of $\mathrm{RB}$, it is worth noting that other E/CDK2 substrates may be the principal mediators of $\mathrm{p} 27^{\prime} \mathrm{s}$ effects on stem cell behavior. Resolution of this issue will require further study.

The second component of the RB pathway that is targeted in gliomas is the G1 cyclin-dependent kinase family members, CDK4 and 6. The gene encoding the $33-\mathrm{kD}$ CDK4 protein maps to chromosome 12q13-14 (Demetrick et al. 1994), whereas that encoding the $38-\mathrm{kD}$ CDK6 protein maps to chromosome 7q21-22 (Bullrich et al. 1995). The CDK4 gene is amplified 10- to 100-fold in nearly $15 \%$ of high-grade gliomas (Reifenberger et al. 1994; Nishikawa et al. 1995). In a small number of cases, tumors without amplification of CDK4 or loss of RB harbor CDK6 amplification, suggesting that the two proteins are functionally equivalent in gliomagenesis (Costello et al. 1997). In cultured mouse astrocytes, overexpression of CDK4 alone promotes immortalization and hyperploidy but not proliferation (Holland et al. 1998b). These data suggest that the induction of proliferation requires additional changes in the $\mathrm{RB}$ pathway and/or cooperative interactions with other growth control pathways. The INK4a tumor suppressor gene maps to 9p21, a region that is lost in many human cancers. This locus, and the syntenic region on mouse chromosome 4, contains two closely linked genes: INK $4 a$ and $I N K 4 b$, which encode $\mathrm{p} 16^{\mathrm{INK} 4 \mathrm{a}}$ and $\mathrm{p} 15^{\mathrm{INK} 4 \mathrm{~b}}$, respectively (Quelle et al. 1995a). These CKIs inhibit the binding of activating Dtype cyclins to CDK4/6 and displace p27, which in turn binds to and inhibits CDK2. The net result is the prevention of CDK-mediated phosphorylation of $\mathrm{pRB}$ and subsequent release into $S$ phase (for review, see Sherr 2000). Importantly, a third protein is also encoded by the
INK4a gene through use of an upstream first exon $(1 \beta)$ and an alternate reading frame in the shared second and third exons with p16 ${ }^{\mathrm{INK} 4 \mathrm{a}}$ (Quelle et al. 1995b). The protein, designated $\mathrm{p} 19^{\mathrm{ARF}}$ (for alternate reading frame), is discussed in greater detail below. p16 $6^{\mathrm{INK} 4 \mathrm{a}}$ is commonly mutated or deleted in human cancer, whereas $\mathrm{p} 15^{\mathrm{INK} 4 \mathrm{~b}}$ appears to be lost primarily as a bystander of larger deletions targeting INK4a (Haber 1997). Loss of $\mathrm{p} 16^{\mathrm{INK} 4 a}$ drives CDK4/6 toward a more highly activated state, resulting in $\mathrm{pRB}$ hyperphosphorylation with associated derepression of pRB-regulated genes and unscheduled entry into $S$ phase. Germline mutations in $\mathrm{p} 16^{\mathrm{INK} 4 \mathrm{a}}$ predispose to melanoma and pancreatic adenocarcinoma but do not appear to promote glioma (Hall and Peters 1996). However, inactivation of $\mathrm{p} 16^{\mathrm{INK} 4 \mathrm{a}}$ is very common in sporadic gliomas, occurring in $50 \%-70 \%$ of high-grade gliomas and in $\sim 90 \%$ of GBM cell lines (James et al. 1991; Olopade et al. 1992), usually via homozygous gene deletion, although coding region point mutations and methylation of 5 ' $\mathrm{CpG}$ islands have been documented (Herman et al. 1995; Costello et al. 1996).

Ectopic expression of $\mathrm{p} 19^{\mathrm{ARF}}$ has been shown to inhibit the growth of human glioma cells in culture (Arap et al. 1997), consistent with its role as a second tumor suppressor in this locus. Its function is distinct from $\mathrm{p} 16^{\mathrm{INK} 4 \mathrm{a}}$ and $\mathrm{p} 15^{\mathrm{INK} 4 \mathrm{~b}}$ in that it does not function as a CKI but rather operates in the p53-MDM2 circuit. Through direct binding to MDM2, p19 ${ }^{\text {ARF }}$ blocks the degradation of $\mathrm{p} 53$, leading to its stabilization. In addition, it enhances apoptosis in a p53-dependent manner (Kamijo et al. 1997; Pomerantz et al. 1998; Stott et al. 1998; Zhang et al. 1998), induces G1 and G2 phase cellcycle arrest (Quelle et al. 1995b; Kamijo et al. 1997), and blocks oncogenic transformation (Pomerantz et al. 1998). Importantly, a recent study of the INK4a locus in a familial syndrome-the melanoma/nervous system tumors-has identified a family with deletion exclusively affecting p19 ARF (Randerson-Moor et al. 2001).

Mice that lack the INK4a/ARF exons 2 and 3 (and hence are doubly null for $\mathrm{p} 16^{\mathrm{INK} 4 \mathrm{a}}$ and p19 $9^{\mathrm{ARF}}$ ) are highly tumor prone, although the relative contribution of each tumor suppressor gene to the phenotype is still unclear (Serrano et al. 1996). INK4a/ARF null mice develop lymphomas and fibrosarcomas by 9 months of age but do not develop malignant gliomas. Of interest, however, is that p19ARF null mice spontaneously developed gliomas at low penetrance, predominantly of low-grade histology (Kamijo et al. 1999). It is not clear to what extent strainspecific modifiers and laboratory environmental differences contribute to the difference in glioma incidence in these two mutant strains.

Taken together, these data provide strong evidence that the dramatic increase in proliferation that is characteristic of the transformation from low-grade to intermediate-grade glioma relates in large part to dysregulation of the RB pathway. Most compelling is the lack of mutational overlap seen among the various members of this pathway, which argues that an important therapeutic goal in the treatment of these tumors must be the restoration of RB pathway control. Similarly, because 
disruption of this pathway underlies further transformation in low-grade tumors, pharmacologic maintenance or restoration of normal $\mathrm{RB}$ function may help thwart malignant progression. Alternatively, RB status may provide opportunities to utilize agents that operate exclusively in RB-deficient tumor cells. For example, adenoviral vectors that contain transgenes driven by the E2F-1 promoter take advantage of the dysregulation of E2F-1 in tumor cells, allowing tumor-selective expression of genes that are under E2F-1 promoter control (Parr et al. 1997).

Chromosome $10 q$ tumor suppressors (PTEN, Mxi1, $D M B T 1) \quad \mathrm{LOH}$ on the long arm of chromosome 10 is a common cytogenetic finding in high-grade gliomas, affecting $75 \%-90 \%$ of these tumors (Fults and Pedone 1993; von Deimling et al. 1993; Lang et al. 1994) as well as several other human cancer types. The PTEN (for phosphatase and tensin homologyl gene, also known as $\bar{M} M A C 1$ (for mutated in multiple advanced cancers) and TEP-1 (for TGF- $\beta$-regulated and epithelial cell-enriched phosphatase), was identified simultaneously by two groups (Li et al. 1997; Steck et al. 1997) as a candidate tumor suppressor gene located at chromosome 10q23.3. Germ-line PTEN mutations have been detected in the autosomal dominant cancer predisposition disorders, Cowden disease, Bannayan-Zonana syndrome, and juvenile polyposis syndrome (Liaw et al. 1997; Eng and Peacocke 1998). These syndromes are notable for harmatomas, benign tumors consisting of normal differentiated cells within highly disorganized tissue architectures. In addition to these benign neoplasia-prone familial syndromes, PTEN mutations are encountered in a wide spectrum of sporadic advanced malignancies, including melanoma and carcinomas of the prostate endometrium, kidney, and lung (Steck et al. 1997; Li and Sun 1998). Among high-grade gliomas, 30\%-44\% demonstrate PTEN mutations (Wang et al. 1997). The high mutation rate of this gene in human cancers, in the face of more benign neoplastic presentation in the familial syndromes, points to the importance of cooperating genetic lesions in unleashing the full potential of PTEN loss of function in oncogenesis, progression, or tumor maintenance. In this regard, PTEN mutations are found in anaplastic astrocytomas and GBMs, both primary and secondary, suggesting that there may be important interactions with the RB and/or EGFR pathways. The protein product of the PTEN gene contains a central domain with perfect sequence consensus to the catalytic region of protein tyrosine phosphatases and an N-terminal domain with extensive homology to tensin and auxilin, which are cytoplasmic proteins involved in interactions with actin filaments at focal adhesions and uncoating of clathrin-coated vesicles, respectively. Correspondingly, PTEN has been demonstrated to possess protein phosphatase activities (Myers et al. 1997; Tamura et al. 1998) and 3 ' phosphoinositol phosphatase activities (Maehama and Dixon 1998). The former is important in regulating cell migration and invasion by directly dephosphorylating focal adhesion kinase (FAK) (Tamura et al. 1998). The latter is directed against the product of PI3-K, PtdIns3,4,5-P3 (Maehama and Dixon 1998), a lipid second messenger required for activation of the AKT/PKB Ser/Thr kinase, which in turn modulates the activity of a variety of downstream proteins shown to play important roles in cell proliferation and survival. Loss of PTEN function in tumor cells and in cells derived from PTEN-deficient mice correlates with an increase in cellular levels of PtdIns-3,4,5-P3, leading to enhanced activation of AKT/ PKB (Myers et al. 1998; Stambolic et al. 1998; Wu et al. 1998). Indeed, it has recently been shown that Ras can cooperate with activated Akt to induce gliomas in mice (Holland, 2001). Introduction of wild-type PTEN into glioma cells containing endogenous mutant alleles causes in vitro and in vivo growth suppression (Furnari et al. 1997; Cheney et al. 1998) but is without effect in cells containing endogenous wild-type PTEN. This growth suppression is caused by a G1 cell-cycle block in GBM cells (Furnari et al. 1998; Li and Sun 1998); however, sensitivity to anoikis (detachment-induced apoptosis) can also be detected (Myers et al. 1998). Furthermore, although some mutants of PTEN that lack growth-suppressive activity are invariably defective for $3^{\prime}$ phosphoinositol phosphatase activity, some retain activity against protein substrates (Furnari et al. 1998; Myers et al. 1998; Vazquez et al. 2000), indicating that the lipid phosphatase activity of PTEN is essential for cellular growth control. PTEN is a bona fide tumor suppressor in the 10q23 region, whose actions appear to be most relevant to processes of glioma progression. It is noteworthy, however, that there exists a discrepancy between $\mathrm{LOH}$ for this chromosomal region and the mutation frequency of the gene (30\%-44\%) (Teng et al. 1997), thus suggesting that other glioma suppressor genes reside in this region. One such candidate is Mxil, a member of the Mad (Mxi1) family of proteins, which are potent antagonists of Myc oncoproteins in vivo (Schreiber-Agus and DePinho 1998; Schreiber-Agus et al. 1998). Mad proteins modulate cellular growth control and may participate in the induction and maintenance of the differentiated state (Grandori et al. 2000). In the CNS, Myc and the Mad family proteins appear to be involved primarily in neuronal differentiation (Queva et al. 1998); a direct role in astrocyte differentiation has not been established. Mxil maps to chromosome 10q24-26, in a region very close to the PTEN locus (Edelhoff et al. 1994), and is mutated in prostate adenocarcinoma (Di Cristofano et al. 1998). In a small series of astrocytomas, Mxil was found to be lost in $15 \%$ of high-grade tumors but was normal in low-grade tumors (Ichimura et al. 1998), consistent with a role in accelerated proliferation seen in the high-grade gliomas. Allelic loss of Mxil was demonstrated in 7 of 11 GBMs, although no somatic mutations were found in any of the coding exons (Wechsler et al. 1997). Expression of Mxil in a human glioma cell line lacking Mxi1 resulted in a decreased growth rate associated with a block of G2-M (Wechsler et al. 1997), as well as morphological changes in the cells. These data support the possibility that Mxil could be functioning as a tumor suppressor gene in gliomas. Mice lacking Mxil develop mild 
prostatic hyperplasia but no frank prostate cancer, lymphoma with a long latency, and no gliomas (SchreiberAgus et al. 1998), implying a need for cooperating genetic events in gliomagenesis. Amplification of Myc is seen only rarely in high-grade gliomas, thus weakening the conclusion that Mxil loss is an important target in gliomagenesis. Perhaps the direct targeting of the RB regulatory pathway is sufficient to induce robust cell-cycle entry without the need for further Myc-enforced cellcycle stimulation. Recent analysis of a homozygous deletion of 10q25-26 in a medulloblastoma cell line has raised the possibility that $D M B T 1$ (for deleted in malignant brain tumors) may be another tumor suppressor gene in this locus. It is a homolog of the scavenger receptor cysteine-rich (SRCR) superfamily (Mollenhauer et al. 1997) and has been shown to be deleted in 50\%-80\% of GBMs and anaplastic astrocytomas (Lin et al. 1998; Sano et al. 1999), frequently without deletion of PTEN. Loss of DMBT1 has also been demonstrated for pancreatic adenocarcinoma, prostate cancer, and small-cell lung cancer. Although its function is unknown, orthologs in mice and rabbit, CRP-ductin and hensin, respectively, have been implicated in epithelial differentiation, immune defense, and polarity reversal (AlAwqati et al. 1999; Takito et al. 1999).

The relative contribution of each of these three genes in gliomagenesis has yet to be determined. It is possible that DMBT1 homologous deletions are simply unmasking constitutional deletion polymorphisms (H. Sasaki and D.N. Louis, unpubl.). However, the high rate of $\mathrm{LOH}$ in an area of chromosome 10 encompassing these three genes in anaplastic astrocytomas and GBMs suggests that loss of two or more tumor suppressors on 10q may help drive the progression from a low- to high-grade glioma phenotype. Particularly intriguing is the finding that $10 \mathrm{q} \mathrm{LOH}$ is frequently found in association with amplification of EGFR in primary GBMs (von Deimling et al. 1992b), raising the possibility that the interaction between EGFR signaling and one or more of these genes/ pathways may be involved in producing the aggressive features of GBM.

Other glioma loci Allelic losses of chromosome 19q occur in $40 \%$ of high-grade astrocytic tumors (von Deimling et al. 1994). Deletion mapping has narrowed the candidate region to the $19 \mathrm{q} 13.3$ between the D19S412 and STD loci, a region that may span as little as $150 \mathrm{~kb}$ (Smith et al. 2000). Although the putative tumor suppressor gene has not yet been identified, three interesting genes reside in this locus. The first is ANOVA (for asstrocytic NOVA-1-like gene encoding a putative astrocytic RNA-binding protein), although mutational analyses of human gliomas have failed to detect deletions or mutations (Ueki et al. 1996). The second, a protein serine threonine phosphatase gene (Yong et al. 1995), and the third, the EHD genes that encode novel members of a highly conserved family of EH (esp 15 homology) domain-containing proteins (Pohl et al. 2000), are potential candidates, although mutational analysis in human gliomas has not yet been performed.
Loss of heterozygosity of chromosome $22 \mathrm{q}$ occurs in $20 \%-30 \%$ of gliomas of all grades (James et al. 1988; Fults et al. 1990), suggesting the presence of a tumor suppressor gene that participates in the early stages of gliomagenesis. The neurofibromatosis 2 (NF2) gene has been mapped near this region. However, sequence analysis of NF2 in astrocytomas of various grades failed to reveal intragenic mutations (Rubio et al. 1994), and cytogenetic and $\mathrm{LOH}$ studies have pinpointed $22 \mathrm{q}$ loss to regions telomeric to NF2 (Ransom et al. 1992). Thus, this potentially relevant tumor suppressor gene(s) remains undefined.

Mutational profile of oligodendrogliomas The molecular genetic profiles of both oligodendroglioma and oligoastrocytoma differ significantly from those of the pure astrocytic gliomas, and as such they are discussed separately here. Oligodendrogliomas display frequent allelic loss of the short arm of chromosome 1 and the long arm of chromosome 19. $1 \mathrm{p}$ and $19 \mathrm{q}$ loss occurs in $~ 50 \%-70 \%$ of both low-grade and anaplastic tumors, suggesting that these are early changes in oligodendroglioma genesis (Louis and Cavenee 2000; Reifenberger et al. 2000). These allelic losses are tightly linked with one another, thus constituting a molecular signature for oligodendroglioma (Cairncross et al. 1998; Ino et al. 2001). Although the $19 \mathrm{q}$ candidate region has been extensively mapped over the past few years (Smith et al. 2000), the 1p and 19q glioma genes remain to be identified. It is notable that once oligodendrogliomas progress to the anaplastic stage, they share progression-associated genetic changes with other high-grade gliomas. Such alterations include deletions of chromosome 9p that include the INK4a/ ARF region, and thus they inactivate p16, ARF, and p15 function; alterations also include losses of chromosome $10 \mathrm{q}$ that are associated with inactivating PTEN gene mutations and occasional p53 gene mutations /Cairncross et al. 1998; Louis and Cavenee 2000; Reifenberger et al. 2000; Ino et al. 2001; H. Sasaki and D.N. Louis, unpubl.).

The molecular genetic basis of oligoastrocytomas is less well defined, primarily because the histological diagnosis of oligoastrocytoma remains subjective (Reifenberger et al. 2000). It is therefore not surprising that most studies of oligoastrocytoma have identified changes characteristic of both oligodendroglial and astrocytic tumors. Such genetic alterations appear to denote subtypes of oligoastrocytoma, with some oligoastrocytomas harboring oligodendroglioma-like genotypes featuring $1 \mathrm{p}$ and $19 \mathrm{q}$ loss and other oligoastrocytomas having more astrocytoma-like genotypes with p53 mutations (Maintz et al. 1997; Reifenberger et al. 2000). As discussed above, it likely that these subtypes reflect differences in the neoplastic cell-of-origin, and thus, a greater understanding of the impact of various genetic mutations on the state of glial differentiation will likely prove invaluable in the diagnosis and potentially in the treatment of these tumors.

\section{The migratory nature of normal and transformed glia}

The ability of glioma cells to widely invade normal brain tissue is a key property of the malignant gliomas (Scherer 
1940) and one that is not seen in any solid tumor that metastasizes to the brain. Invasion does not correlate with glioma grade, since low-grade astrocytomas invade extensively throughout normal brain tissue without disrupting brain cytoarchitecture or neuronal function. Glioma cell invasion bears striking resemblance to the robust migration of glial and neuronal cells during embryogenesis (Hatten 1999), and it likely that the mechanisms underlying invasion simply reflect a reactivation of the mechanisms regulating early glial migration.

During embyrogenesis, cells migrate out of the subventricular zone in a radial pattern associated with the radial glia lattice-like scaffolding, as discussed above. Subsequently, migration occurs in a transverse pattern in parallel with the surface of the brain, possibly along axonal processes. Migration ceases by postnatal day 14 (Levison et al. 1993); it is temporally related to collapse of the radial glial scaffold after terminal differentiation of these cells (Voigt 1989; Kakita and Goldman 1999). In the adult CNS neurons, astrocytes and oligodendrocytes are fixed in position and do not migrate (Small 1992). However, it has been demonstrated experimentally that brain injury (e.g., cortical stab or ischemic injury) induces migration of nestin-positive cells from the subventricular zone to the site of injury (Weinstein et al. 1996; Johansson et al. 1999; Namiki and Tator 1999; Takagi et al. 1999; Liu et al. 2000; Magavi et al. 2000). These presumed neural stem cells and glial progenitors then undergo terminal differentiation into astrocytes. The mechanism by which these cells migrate throughout the substance of the mature brain, devoid of a radial glial lattice, is not known. However, this finding lends support to the concept that there are cells in the adult brain, most likely the neural stem cell and glial progenitor pools, that retain the ability to migrate under specific conditions. Whether the genetic pathways governing migration can be dysregulated by malignant transformation of a differentiated astrocyte or glial precursor is unknown, but it is reasonable to assume that such pathways represent common targets in gliomagenesis.

A recent study exploited the migratory property of neural stem cells for delivery of a cytotoxic drug to remote sites of implanted tumor cells (Aboody et al. 2000). It was demonstrated that neural stem cells and tumor cells co-clustered at distances remote from the tumor injection site, raising the intriguing possibility that both tumor cells and neural stem cells migrate along similar substrate pathways in the adult brain. The most frequent route of invasion of glial tumor cells is along white matter tracts and basement membrane of blood vessels. Whether this route offers a path of least resistance or biochemical substrates mediate adhesion and promote migration is unclear. Invasion and migration in glial tumors differ from the process in other tumors in which local spread is very limited and dissemination occurs hematogenously or via the lymphatic system. It has been shown experimentally that glioma cells lack the ability to penetrate the basement membrane of blood vessels (Bernstein and Woodard 1995), which could possibly explain the paucity of systemic metastases in gliomas. Ad- ditionally, it appears that cells gaining access to the blood via a disrupted blood vessel within the tumor are unable to establish robust tumor growth outside the CNS, again establishing major biological differences between gliomas and other solid tumors. It has been demonstrated that invasion of non-glioma solid tumors requires proteases to degrade the surrounding stromal cells and extracellular matrix (Mignatti and Rifkin 1993). The matrix metalloproteinases (MMPs) appear to play an important role in this mechanism; as a result, this has been an intense area of both basic and clinical investigation (for review, see Uhm et al. 1997). However, the role of MMPs in glioma invasion is less clear. Immunohistochemical data have shown that MMP-2 and MMP-9 are highly expressed in gliomas although associated only with anaplastic astrocytomas and GBMs (Nakagawa et al. 1994; Nakada et al. 1999). MMP-9 immunoreactivity is most intensely associated with endothelial vessels and not with tumor cells, likely reflecting the onset of angiogenesis in GBM (Nakagawa et al. 1994). Complementing the increase in MMPs, the tissue inhibitors of MMPs (TIMP1 and 2) are expressed at low levels in malignant gliomas (Yamamoto et al. 1994). Other non-MMP proteases, including urokinase-type plasminogen activator (uPA) (Landau et al. 1994; Yamamoto et al. 1994) and cystein proteases (e.g., cathepsin B) (McCormick 1993), are elevated in high-grade gliomas (for review, see Uhm et al. 1977). Despite these findings, the role of proteases in glioma invasion remains unclear because low-grade astrocytomas diffusely infiltrate the brain, despite relatively normal levels of the proteases. An understanding of the molecular events driving migration in adult brain in response to normal stimuli should provide insights into how these mechanisms are co-opted by glioma cells, resulting in the highly infiltrative nature characteristic of these tumors. Most informative will be a greater understanding of whether glioma cell migration is a property of the tumor cell-of-origin (i.e., stem cells or glial precursors) that persists in the adult brain or, rather, is a reactivation of the migratory machinery operative during development.

\section{Vascular development and GBM angiogenesis}

The striking and dramatic induction of angiogenesis in GBM has fueled the speculation that progression to GBM requires activation of angiogenesis and has stimulated significant efforts in the development of agents that will block this process. In particular, two pathways have received considerable attention. They are vascular endothelial growth factor (VEGF) and its receptors, VEGFR1 (Flt-1) and VEGFR2 (Flk-1), and the angiopoietins and their Tie 2 receptor system. VEGF has been shown to be critical for the earliest stages of vasculogenesis, promoting endothelial cell proliferation, differentiation, migration, and tubular formation. Gene targeting studies have shown that deficiency of VEGF, Flt-1, or Flk-1 results in early embryonic lethality caused by defects in angiogenesis and vasculogenesis (Shalaby et al. 1995; Carmeliet et al. 1996; Ferrara et al. 1996). Specific VEGF inhibitors 
have recently been introduced into clinical glioma trials, and results are forthcoming. Encouragingly, the putative antiangiogenic agent, thalidomide, has been shown to have activity in patients with recurrent high-grade gliomas (Fine et al. 2000).

In the case of the angiopoeitins, genetic studies in the mouse have shown that angiopoietin-1 (Ang1) promotes remodeling and stabilization of VEGF-induced vessels (Sato et al. 1995; Suri et al. 1996) through interactions between endothelial cells and surrounding pericytes and extracellular matrix. Angiopoietin-2 (Ang2) appears to be a natural antagonist of Ang1, responsible for destabilization of mature vessels in the context of vessel regression or angiogenesis in a VEGF-dependent manner. Thus, Ang2 expression results in reversal of the maturation process mediated by Ang1, leading to disruption of interactions between endothelial cells, pericytes, and the extracellular matrix. In the presence of VEGF activity, the Ang2 effect is followed by sprouting and ingrowth of new vessels (i.e., neovascularization). However, in the absence of concomitant VEGF expression, Ang2-mediated destabilziation leads to regression of blood vessels. On the basis of these results, one can easily envision a therapeutic strategy targeted to the tumor in which Ang-2 is induced in the setting VEGF inhibition, a combination predicted to induce vascular collapse in the tumors. The strong genetic validation has justified ongoing angiopoeitin-directed drug development initiatives.

During normal brain development, the primitive vascular plexus formed by mesoderm-derived angioblasts envelops the brain without penetrating the parenchyma. At gestational day E11 in the mouse, vascular sprouts originating from the perineural plexus extend radially into the neuroectoderm toward the ventricles, a chemotactic extension driven by high levels of VEGF in the ventricular zone (Breier et al. 1992). Consistent with the peak of VEGF expression that occurs soon after birth and its subsequent down-regulation by post-natal days 15-20 in rodents (Breier et al. 1992), endothelial cell proliferation declines postnatally and increased brain size is matched by elongation of preexisting vessels. Notably, the spatial and temporal pattern of VEGF expression correlates tightly with that of EGFR, specifically in the subventricular zone during the latter half of embryonic development (see above). This observation, coupled with the finding of EGF-dependent VEGF expression in cultured astrocytes (Goldman et al. 1993), suggests a potential link between EGFR signaling and VEGF activity, a provocative link that is further strengthened by the appearance of EGFR mutation or amplification concomitant with induction of angiogenesis in GBM lesions.

Although the mechanism driving the angiogenic burst in GBM has yet to be elucidated, evidence indeed exists pointing to a pivotal role for VEGF (Millauer et al. 1994; Cheng et al. 1996). It has long been held that the rapid proliferative rate of GBM creates local ischemia and hypoxia, leading to induction of angiogenesis that is mediated by VEGF activity. This is based on the observation that marked VEGF expression is localized to regions of perinecrotic (palisading) cells at expanding edges of the tumor (Plate et al. 1992). However, a recent study has shed doubt on this dogma. Zagzag et al. (2000) demonstrated that glioma cells implanted into murine brain actually hone initially to existing vasculature. This cooptation of host vessels eventually leads to induction of Ang2 expression in the host endothelial cells and Ang2-mediated destabilization (as manifested by the lifting of astrocytic foot processes away from endothelial cells and disruption of the normal pericyte cuffing) and subsequent regression of existing vessels and necrosis. Tumor cell necrosis resulting from vascular regression and hypoxia then appeared to trigger expression of VEGF and the onset of angiogenesis. These intriguing findings support the view that a key mechanism in early tumor angiogenesis may be a direct effect of the tumor cells on existing blood vessels rather than the orthodox view of new blood vessel growth into the hypoxemic growing tumor bed. Although genetic validation of an essential role for VEGF in mediating the angiogenic burst in GBM and its functional relationship to EGFR signaling is still lacking, findings from developmental, cell culturebased, and the orthotopic explant tumor studies described above strongly support the hypothesis that acquisition of EGFR activation (via mutation or amplification) in GBM may drive the induction of angiogenesis through its functional link to VEGF.

\section{Genetically engineered mouse models of human glioma}

The cardinal biological features of malignant gliomas in humans, including their diffusely infiltrative nature and their remarkable propensity toward further malignant progression, have been among the major impediments to developing successful therapies for gliomas. The creation of murine models that recapitulate these biological features based on the relevant genetics of malignant gliomas will find great and broad utility in the study of gliomas as well as in the development and testing of targeted therapeutics. Such models will provide a system in which to investigate the biological mechanisms underlying tumorigenesis and tumor maintenance as well as provide a validated platform for the functional screening of candidate genes identified through large-scale genomic analysis of tumor specimens. The need for accurate models is perhaps most acute in preclinical testing, where experimental data often determine the fate of a drug in development. It is widely appreciated that data obtained in a refined mouse model of human gliomas should diminish the exposure of patients to ineffective drugs that would otherwise go through phase I/II clinical trials. In addition, accurate models may help define the clinical tumor grade in which an agent or combination of agents may be most effective.

The ideal mouse glioma models should be built on known genetic alterations described in human gliomas and be characterized by several key features, including tumor cells displaying glial differentiation, diffuse, single-cell infiltration of the surrounding brain parenchyma (including the so-called secondary structures of Scherer), histological progression from low-grade to 
high-grade malignancy, neovascular proliferation (sometimes in the form of so-called glomeruloid blood vessel formations), and regional necrosis (often with palisading of tumor cells around the necrosis). However, a model that recapitulates the clinical features of the disease (i.e., is a phenocopy) but does not reflect the genetic basis of the tumors (i.e., is not a genocopy) may also find use in the analysis of mechanisms underlying invasion, angiogenesis, necrosis, and tumor-extracellular matrix interactions. Novel therapies developed to block these biological pathways could be tested in such a model. Similarly, a model that recapitulates the genetics but lacks several of the clinical features of the tumor (i.e., is a genocopy but not phenocopyl is an equally valuable system. For example, a tumor driven by PDGF could be used to study the downstream targets and the biological consequences of activation of the pathway. In preclinical testing, this would be an excellent model to study the effects of a specific RTK inhibitor, for example, PDGF-R or EGFR. Finally, genocopy models that use inducible or conditional systems would be ideal to study the role of specific genetic mutations in tumor progression and maintenance. For example, a mouse model that is initiated by induction of PDGF overexpression could be used to study the importance of PDGF in tumor maintenance by switching off PDGF and observing the biological effects of PDGF withdrawal on the established tumor.

Until recently, the most widely used murine brain tumor models have been orthotopic grafts of tumor cell lines, often using glioma cell lines that retained little in the way of glial differentiation. In addition, these glioma models failed to produce the cardinal features of malignant gliomas, such as single-cell infiltration, and to exhibit histological progression. As such, they are proven suboptimal for the dissection of the molecular pathways underlying gliomagenesis and progression and presumably for preclinical testing.

Genetically engineered murine glioma models have been generated using different approaches; it is remarkable and extraordinarily encouraging that a number of these models have recapitulated several of the cardinal histological features, albeit to varying degrees. These models have used different genetic approaches, none to date providing a true genocopy of the human tumor but each using one or more of the genes known to be associated with malignant gliomas (see above the discussions of the relevant genetic mutations). Taken together, the models illustrate a number of important principles in glioma biology. Loss of a single tumor suppressor gene or overexpression of an oncogene is insufficient to induce high-grade gliomas with high penetrance. Mice deficient in p19ARF develop low- but not high-grade gliomas (Kamijo et al. 1999), again emphasizing the need to construct compound mutant strains in the generation of GBM. This principle has been confirmed for several combinations of genetic lesions. For example, although gliomas were not observed in p53 or NF1 KO, mice doubly heterozygous for p53 and NF1 develop low- to intermediate-grade gliomas. Interestingly, in studying these compound mutants, it was shown that modifying muta- tions was important in gliomagenesis (Reilly et al. 2000). Specifically, there were significant differences in glioma penetrance, depending on the strain background. However, despite the variance in penetrance, there was no significant difference in tumor pathology, suggesting that the major biological effects of dysregulating these pathways were not altered by the modifiers. Evidence of tumor progression was shown in the GFAP-v-src model in which early lesions were characterized by dysplastic changes, whereas overt astrocytomas developed later and were of higher grade (Weissenberger et al. 1997).

As discussed above, the importance of cell-of-origin is revealed in these engineered models, because it appears that the ability to transform a cell is influenced by the target cell in each model. Overexpression of activated EGFR in the setting of INK4a deficiency induced gliomas with much higher penetrance when targeted to the nestin-expressing cells in the early postnatal brain (Holland et al. 1998a). When targeted to the GFAP-expressing cells, few tumors resulted (Holland et al. 1998a), suggesting that the neural stem cell is more permissive to the transforming effects of EGFR overexpression in the setting of INK4a deficiency. Similar results were obtained when Ras and activated Akt were targeted to nestin-positive rather than GFAP-positive cells (Holland et al. 2000). Interestingly, although there was some variation between the histological features of the gliomas generated by these two different combinations of genetic mutations, each generated highly invasive, intermediate- to high-grade tumors. These data illustrate that the results of dysregulating various family members of a pathway or regulatory machinery may have similar biological consequences.

The issue of cell-of-origin is also raised in a study of PDGF overexpression in early postnatal murine brains. PDGF was delivered in a retroviral system and packaged with Moloney virus; it yielded gliomas with high penetrance (Uhrbom et al. 2000). Although it is possible that high levels of PDGF expression alone could induce gliomas, another explanation for these findings is that the tumors resulted from the combination of PDGF overexpression and proviral mutagenesis. The pathological features of these tumors, although similar to GBM, had a preponderance of oligodendrocytes, were nestin positive, and most closely resembled high-grade oligodendrogliomas. In culture, the tumor cells were immunoreactive for nestin and other markers for the oligodendroglial precursor lineage, suggesting that these tumors resulted from malignant transformation of an oligodendrocyte precursor (Uhrbom et al. 2000). This is perhaps not surprising given the prominent role for PDGF in oligodendrocyte development. However, it is surprising when one considers the prominent role for PDGF/R in human low-grade astrocytomas and its relatively insignificant role in human oligodendrogliomas as discussed above. This study raises the important issue of the role of cooperating genetic events in determining the biological phenotype and again raises the question of impact of a genetic mutation or combination of mutations on a given state of cellular differentiation. These novel mu- 
rine models have for the first time provided valid histological models of malignant glioma, most of which are in need of further refinement, and have illustrated the value of such an approach-an expanded scientific horizon and a period of true promise.

\section{Future Directions}

The goal in neuro-oncology is clear: to understand the biology of malignant gliomas on a level that leads to the development of targeted curative therapy. The challenges to achieving this goal may appear to be considerable given the complexity of the tumors and the need for a multidisciplinary approach to the problem. However, as outlined throughout this review, despite the significant gaps in our understanding, a wealth of information exists about the clinical and biological behavior of the tumors, the genetic pathways involved in gliomagenesis, and basic developmental neurobiology. The challenge now is to integrate the information in these various disciplines in a way that provides a comprehensive view of the cellular and genetic mechanisms underlying the tumor biology.

Although developmental neurobiology and neuro-oncology have traditionally been separate disciplines, molecular analysis of mechanisms underlying CNS development has already yielded significant insight into tumorigenesis. The most well-characterized example is the Sonic hedgehog pathway. This pathway is essential for proliferation of granule neuron precursors during development of the cerebellum (Dahmane and Ruiz-i-Altaba 1999; Wallace 1999; Wechsler-Reya and Scott 1999) and is etiologic in perhaps $10 \%-20 \%$ of cases of the human cerebellar tumor, medulloblastoma (Hahn et al. 1996; Johnson et al. 1996; Raffel et al. 1997). As presented in this review, we find that there are striking similarities between glial development and the unique features of the malignant gliomas. It is clear that the opportunities for integrated investigation are substantial and will likely yield information that can advance the knowledge base in both neurobiology and neuro-oncology. The ability to grow neural stem cells, astrocytes, and oligodendrocytes in culture will provide neuro-oncologists with the opportunity to dissect the genetic pathways involved in various aspects of the differentiation and dedifferentiation of these cells. Genes identified in these pathways can be examined in human tumor specimens, and the functional relevance in gliomas can be tested using various in vitro systems and the mouse models.

The rapid advancements in genomic technology and mouse engineering have created an unprecedented opportunity in neuro-oncology. The contributions made to glioma biology from a multidisciplinary approach to unraveling the complex pathways underlying the clinical features of malignant gliomas will lead to meaningful progress for patients with these devastating tumors.

\section{Acknowledgments}

We thank Drs. Lynda Chin, Nicole Schreiber-Agus, Kristen Senechal, and James MingJian You for critical reading of the manuscript. We are grateful to Dr. Norman Sharpless for helpful discussions and drafts of Figure 4 and to Joseph DePinho for the graphic design and preparation of the Figures and Table, and to Suzanne Markloff for assistance with preparation of the manuscript. The authors were supported by grants from NIH, ACS, V Foundation, Dana Foundation, and the Ludwig Institute. RAD is an ACS Research Professor.

\section{References}

Aboody, K.S., Brown, A., Rainov, N.G., Bower, K.A., Liu, S., Yang, W., Small, J.E., Herrlinger, U., Ourednik, V., Black, P.M., et al. 2000. Neural stem cells display extensive tropism for pathology in adult brain: Evidence from intracranial gliomas. Proc. Nat1. Acad. Sci. 97: 12846-12851.

Al-Awqati, Q., Vijayakumar, S., Takito, J., Hikita, C., Yan, L., and Wiederholt, T. 1999. Terminal differentiation in epithelia: The Hensin pathway in intercalated cells. Semin. Nephrol. 19: 415-420.

Arap, W., Knudsen, E., Sewell, D.A., Sidransky, D., Wang, J.Y., Huang, H.J., and Cavenee, W.K. 1997. Functional analysis of wild-type and malignant glioma derived CDKN2A $\beta$ alleles: Evidence for an RB-independent growth suppressive pathway. Oncogene 15: 2013-2020.

Barak, Y., Gottlieb, E., Juven-Gershon, T., and Oren, M. 1994. Regulation of $\mathrm{mdm} 2$ expression by p53: Alternative promoters produce transcripts with nonidentical translation potential. Genes \& Dev. 8: 1739-1749.

Bernstein, J.J. and Woodard, C.A. 1995. Glioblastoma cells do not intravasate into blood vessels. Neurosurgery 36: 124132, discussion 132.

Biernat, W., Aguzzi, A., Ulrich, S., Grant, J., Kleihues, P., and Hegi, M. 1995. Identical mutations of the p53 tumor supressor gene in the gliomatous and the sarcomatous components of gliosarcomas suggest a common origin from glial cells. $I$. Neuropathol. Exp. Neurol. 54: 651-656.

Bigner, S.H., Humphrey, P.A., Wong, A.J., Vogelstein, B., Mark, J., Friedman, H.S., and Bigner, D.D. 1990. Characterization of the epidermal growth factor receptor in human glioma cell lines and xenografts. Cancer Res. 50: 8017-8022.

Bilato, C., Pauly, R.R., Melillo, G., Monticone, R., GorelickFeldman, D., Gluzband, Y.A., Sollott, S.J., Ziman, B., Lakatta, E.G., and Crow, M.T. 1995. Intracellular signaling pathways required for rat vascular smooth muscle cell migration. Interactions between basic fibroblast growth factor and platelet-derived growth factor. J. Clin. Invest. 96: 19051915.

Bjornson, C.R., Rietze, R.L., Reynolds, B.A., Magli, M.C., and Vescovi, A.L. 1999. Turning brain into blood: A hematopoietic fate adopted by adult neural stem cells in vivo. Science 283: 534-537.

Bouchard, J. and Pierce, C.B. 1960. Radiation therapy in the management of neoplasms of the central nervous system, with a special note in regard to children: Twenty years experience. Am. J. Roentgenol. 84: 610-628.

Brat, D.J., James, C.D., Jedlicka, A.E., Connolly, D.C., Chang, E., Castellani, R.J., Schmid, M., Schiller, M., Carson, D.A., and Burger, P.C. 1999. Molecular genetic alterations in radiation-induced astrocytomas. Am. J. Pathol. 154: 14311438.

Breier, G., Albrecht, U., Sterrer, S., and Risau, W. 1992. Expression of vascular endothelial growth factor during embryonic angiogenesis and endothelial cell differentiation. Development 114: 521-532.

Bressler, J.P., Grotendorst, G.R., Levitov, C., and Hjelmeland, 
L.M. 1985. Chemotaxis of rat brain astrocytes to platelet derived growth factor. Brain Res. 344: 249-254.

Bullrich, F., MacLachlan, T.K., Sang, N., Druck, T., Veronese, M.L., Allen, S.L., Chiorazzi, N., Koff, A., Heubner, K., Croce, C.M., et al. 1995. Chromosomal mapping of members of the cdc2 family of protein kinases, cdk3, cdk6, PISSLRE, and PITALRE, and a cdk inhibitor, p27Kip1, to regions involved in human cancer. Cancer Res. 55: 1199-1205.

Burrows, R.C., Wancio, D., Levitt, P., and Lillen, L. 1997. Response diversity and the timing of progenitor cell maturation are regulated by developmental changes in EGFR expression in the cortex. Neuron 19: 251-267.

Cairncross, J.G., Ueki, K., Zlatescu, M.C., Lisle, D.K., Finkelstein, D.M., Hammond, R.R., Silver, J.S., Stark, P.C., Macdonald, D.R., Ino, Y., Ramsay, D.A., and Louis, D.N. 1998. Specific genetic predictors of chemotherapeutic response and survival in patients with anaplastic oligodendrogliomas. J. Natl. Cancer Inst. 90: 1473-1479.

Calver, A.R., Hall, A.C., Yu, W.P., Walsh, F.S., Heath, J.K., Betsholtz, C., and Richardson, W.D. 1998. Oligodendrocyte population dynamics and the role of PDGF in vivo. Neuron 20: 869-882.

Carmeliet, P., Mackman, N., Moons, L., Luther, T., Gressens, P., Van Vlaenderen, I., Demunck, H., Kasper, M., Breier, G., Evrard, P., et al. 1996. Role of tissue factor in embryonic blood vessel development. Nature 383: 73-75.

Cheney, I.W., Johnson, D.E., Vaillancourt, M.T., Avanzini, J., Morimoto, A., Demers, G.W., Wills, K.N., Shabram, P.W., Bolen, J.B., Tavtigian, S.V., et al. 1998. Suppression of tumorigenicity of glioblastoma cells by adenovirus-mediated MMAC1/PTEN gene transfer. Cancer Res. 58: 2331-2334.

Cheng, S.Y., Huang, H.J., Nagane, M., Ji, X.D., Wang, D., Shih, C.C., Arap, W., Huang, C.M., and Cavenee, W.K. 1996. Suppression of glioblastoma angiogenicity and tumorigenicity by inhibition of endogenous expression of vascular endothelial growth factor. Proc. Natl. Acad. Sci. 93: 8502-8507.

Cheng, T., Rodrigues, N., Dombkowski, D., Stier, S., and Scadden, D.T. 2000. Stem cell repopulation efficiency but not pool size is governed by p27kip1. Nat. Med. 6: 1235-1240.

Chung, R., Whaley, J., Kley, N., Anderson, K., Louis, D., Menon, A., Hettlich, C., Freiman, R., Hedley-Whyte, E.T., Martuza, R., et al. 1991. TP53 gene mutations and 17p deletions in human astrocytomas. Genes Chromosomes Cancer 3: 323331.

Claesson-Welsh, L. 1994. Platelet-derived growth factor receptor signals. J. Biol. Chem. 269: 32023-32026.

Clarke, D., Johansson, C., Wilbertz, J., Veress, B., Nilsson, E., Karlstrom, H., Lendahl, U., and Frisen, J. 2000. Generalized potential of adult neural stem cells. Science 288: 1660-1663.

Costello, J.F., Berger, M.S., Huang, H.S., and Cavenee, W.K. 1996. Silencing of p16/CDKN2 expression in human gliomas by methylation and chromatin condensation. Cancer Res. 56: 2405-2410.

Costello, J.F., Plass, C., Arap, W., Chapman, V.M., Held, W.A., Berger, M.S., Su Huang, H.J., and Cavenee, W.K. 1997. Cyclin-dependent kinase 6 (CDK6) amplification in human gliomas identified using two-dimensional separation of genomic DNA. Cancer Res. 57: 1250-1254.

Craig, C.G., Tropepe, V., Morshead, C.M., Reynolds, B.A., Weiss, S., and van der Kooy, D. 1996. In vivo growth factor expansion of endogenous subependymal neural precursor cell populations in the adult mouse brain. I. Neurosci. 16: 2649-2658.

Dahmane, N. and Ruiz-i-Altaba, A. 1999. Sonic hedgehog regulates the growth and patterning of the cerebellum. Development 126: 3089-3100.
Demetrick, D.J., Zhang, H., and Beach, D.H. 1994. Chromosomal mapping of human CDK2, CDK4, and CDK5 cell cycle kinase genes. Cytogenet. Cell Genet. 66: 72-74.

Di Cristofano, A., Pesce, B., Cordon-Cardo, C., and Pandolfi, P.P. 1998. Pten is essential for embryonic development and tumour suppression. Nat. Genet. 19: 348-355.

Durand, B., Fero, M.L., Roberts, J.M., and Raff, M.C. 1998. p27Kipl alters the response of cells to mitogen and is part of a cell-intrinsic timer that arrests the cell cycle and initiates differentiation. Curr. Biol. 8: 431-440.

Edelhoff, S., Ayer, D.E., Zervos, A.S., Steingrimsson, E., Jenkins, N.A., Copeland, N.G., Eisenman, R.N., Brent, R., and Disteche, C.M. 1994. Mapping of two genes encoding members of a distinct subfamily of MAX interacting proteins: MAD to human chromosome 2 and mouse chromosome 6, and MXI1 to human chromosome 10 and mouse chromosome 19. Oncogene 9: 665-668.

Ekstrand, A.J., James, C.D., Cavenee, W.K., Seliger, B., Pettersson, R.F., and Collins, V.P. 1991. Genes for epidermal growth factor receptor, transforming growth factor $\alpha$, and epidermal growth factor and their expression in human gliomas in vivo. Cancer Res. 51: 2164-2172.

El-Obeid, A., Bongcam-Rudloff, E., Sorby, M., Ostman, A., Nister, M., and Westermark, B. 1997. Cell scattering and migration induced by autocrine transforming growth factor $\alpha$ in human glioma cells in vitro. Cancer Res. 57: 5598-5604.

Eng, C. and Peacocke, M. 1998. PTEN and inherited hamartoma-cancer syndromes [letter]. Nat. Genet. 19: 223.

Facchiano, A., De Marchis, F., Turchetti, E., Facchiano, F., Guglielmi, M., Denaro, A., Palumbo, R., Scoccianti, M., and Capogrossi, M.C. 2000. The chemotactic and mitogenic effects of platelet-derived growth factor-BB on rat aorta smooth muscle cells are inhibited by basic fibroblast growth factor. J. Cell Sci. 113: 2855-2863.

Ferrara, N., Carver-Moore, K., Chen, H., Dowd, M., Lu, L., O'Shea, K.S., Powell-Braxton, L., Hillan, K.J., and Moore, M.W. 1996. Heterozygous embryonic lethality induced by targeted inactivation of the VEGF gene. Nature 380: 439442.

Fidler, P., Schuette, K., Asher, R., Dobbertin, A., Thorton, S., Calle-Patino, Y., Muir, E., Levine, J., Geller, H., Rogers, J., et al. 1999. Comparing astrocytic cell lines that are inhinitory of permissive for axon growth: The major axon-inhibitory proteoglycan is NG2. J. Neurosci. 19: 8778-8788.

Fine, H.A., Figg, W.D., Jaeckle, K., Wen, P.Y., Kyritsis, A.P., Loeffler, J.S., Levin, V.A., Black, P.M., Kaplan, R., Pluda, J.M., et al. 2000. Phase II trial of the antiangiogenic agent thalidomide in patients with recurrent high-grade gliomas. $J$. Clin. Oncol. 18: 708-715.

Forsberg-Nilsson, K., Behar, T.N., Afrakhte, M., Barker, J.L., and McKay, R.D. 1998. Platelet-derived growth factor induces chemotaxis of neuroepithelial stem cells. J. Neurosci. Res. 53: 521-530.

Fricker-Gates, R.A., Winkler, C., Kirik, D., Rosenblad, C., Carpenter, M.K., and Bjorklund, A. 2000. EGF infusion stimulates the proliferation and migration of embryonic progenitor cells transplanted in the adult rat striatum. Exp. Neurol. 165: 237-247.

Fults, D. and Pedone, C. 1993. Deletion mapping of the long arm of chromosome 10 in glioblastoma multiforme. Genes Chromosomes Cancer 7: 173-177.

Fults, D., Pedone, C.A., Thomas, G.A., and White, R. 1990. Allelotype of human malignant astrocytoma. Cancer Res. 50: $5784-5789$.

Furnari, F.B., Lin, H., Huang, H.S., and Cavenee, W.K. 1997. Growth suppression of glioma cells by PTEN requires a func- 
tional phosphatase catalytic domain. Proc. Natl. Acad. Sci. 94: 12479-12484.

Furnari, F.B., Huang, H.J., and Cavenee, W.K. 1998. The phosphoinositol phosphatase activity of PTEN mediates a serumsensitive G1 growth arrest in glioma cells. Cancer Res. 58: 5002-5008.

Fuse, T., Tanikawa, M., Nakanishi, M., Ikeda, K., Tada, T., Inagaki, H., Asai, K., Kato, T., and Yamada, K. 2000. p27Kip1 expression by contact inhibition as a prognostic index of human glioma. J. Neurochem. 74: 1393-1399.

Galli, R., Borello, U., Gritti, A., Minasi, M.G., Bjornson, C., Coletta, M., Mora, M., De Angelis, M.G., Fiocco, R., Cossu, G., et al. 2000. Skeletal myogenic potential of human and mouse neural stem cells. Nat. Neurosci. 3: 986-991.

Gates, M.A., Thomas, L.B., Howard, E.M., Laywell, E.D., Sajin, B., Faissner, A., Gotz, B., Silver, J., and Steindler, D.A. 1995. Cell and molecular analysis of the developing and adult mouse subventricular zone of the cerebral hemispheres. $J$. Comp. Neurol. 361: 249-266.

Goldman, C.K., Kim, J., Wong, W.L., King, V., Brock, T., and Gillespie, G.Y. 1993. Epidermal growth factor stimulates vascular endothelial growth factor production by human malignant glioma cells: A model of glioblastoma multiforme pathophysiology. Mol. Biol. Cell 4: 121-133.

Gonzalez-Fernandez, F., Lopes, M.B., Garcia-Fernandez, J.M., Foster, R.G., De Grip, W.J., Rosemberg, S., Newman, S.A., and VandenBerg, S.R. 1992. Expression of developmentally defined retinal phenotypes in the histogenesis of retinoblastoma. Am. J. Pathol. 141: 363-375.

Grandori, C., Cowley, S.M., James, L.P., and Eisenman, R.N 2000. The Myc/Max/Mad network and the transcriptional control of cell behavior. Annu. Rev. Cell Dev. Biol. 16: 653699.

Guha, A., Feldkamp, M.M., Lau, N., Boss, G., and Pawson, A. 1997. Proliferation of human malignant astrocytomas is dependent on Ras activation. Oncogene 15: 2755-2765.

Haber, D.A. 1997. Splicing into senescence: The curious case of p16 and p19ARF. Cell 91: 555-558.

Hahn, H., Wicking, C., Zaphiropoulous, P.G., Gailani, M.R., Shanley, S., Chidambaram, A., Vorechovsky, I., Holmberg, E., Unden, A.B., Gillies, S., et al. 1996. Mutations of the human homolog of Drosophila patched in the nevoid basal cell carcinoma syndrome. Cell 85: 841-851.

Hall, M. and Peters, G. 1996. Genetic alterations of cyclins, cyclin-dependent kinases, and Cdk inhibitors in human cancer. Adv. Cancer Res. 68: 67-108.

Hatten, M.E. 1990. Riding the glial monorail: A common mechanism for glial-guided neuronal migration in different regions of the developing mammalian brain. Trends Neurosci. 13: 179-184.

- 1999. Central nervous system neuronal migration. Annu. Rev. Neurosci. 22: 511-539.

Haupt, Y., Maya, R., Kazaz, A., and Oren, M. 1997. Mdm2 promotes the rapid degradation of p53. Nature 387: 296-299.

Heldin, C. 1996. Protein tyrosine kinase receptors. Cancer Surveys 27: 7-24.

Heldin, C.H. and Westermark, B. 1990. Platelet-derived growth factor: Mechanism of action and possible in vivo function. Cell Regul. 1: 555-566.

Henson, J.W., Schnitker, B.L., Correa, K.M., von Deimling, A., Fassbender, F., Xu, H.J., Benedict, W.F., Yandell, D.W., and Louis, D.N. 1994. The retinoblastoma gene is involved in malignant progression of astrocytomas. Ann. Neurol. 36: 714-721.

Herman, J.G., Merlo, A., Mao, L., Lapidus, R.G., Issa, J.P., Davidson, N.E., Sidransky, D., and Baylin, S.B. 1995. Inactiva- tion of the CDKN2/p16/MTS1 gene is frequently associated with aberrant DNA methylation in all common human cancers. Cancer Res. 55: 4525-4530.

Hermanson, M., Funa, K., Hartman, M., Claesson-Welsh, L., Heldin, C.H., Westermark, B., and Nister, M. 1992. Plateletderived growth factor and its receptors in human glioma tissue: Expression of messenger RNA and protein suggests the presence of autocrine and paracrine loops. Cancer Res. 52: 3213-3219.

Hermanson, M., Funa, K., Koopmann, J., Maintz, D., Waha, A., Westermark, B., Heldin, C.H., Wiestler, O.D., Louis, D.N., von Deimling, A., et al. 1996. Association of loss of heterozygosity on chromosome $17 \mathrm{p}$ with high platelet-derived growth factor $\alpha$ receptor expression in human malignant gliomas. Cancer Res. 56: 164-171.

Holland, E., Hively, W., DePinho, R.A., and Varmus, H. 1998a. A constitutively active epidermal growth factor receptor cooperates with disruption of G1 cell-cycle arrest pathways to induce glioma-like lesions in mice. Genes \& Dev. 112: 36753685.

Holland, E., Hively, W., Gallo, V., and Varmus, H. 1998b. Modeling mutations in the G1 arrest pathway in human gliomas: Overexpression of CDK4 but not loss of INK4a-ARF induces hyperploidy in cultured mouse astrocytes. Genes \& Dev. 12: 3644-3649.

Holland, E.C., Celestino, J., Dai, C., Schaefer, L., Sawaya, R.E., and Fuller, G.N. 2000. Combined activation of Ras and Akt in neural progenitors induces glioblastoma formation in mice. Nat. Genet. 25: 55-57.

Huang, H., Colella, S., Kurrer, M., Yonekawa, Y., Kleihues, P., and Ohgaki, H. 2000. Gene expression profiling of low-grade diffuse astrocytomas by cDNA arrays. Cancer Res. 60: 6868 6874.

Humphrey, P.A., Wong, A.J., Vogelstein, B., Zalutsky, M.R., Fuller, G.N., Archer, G.E., Friedman, H.S., Kwatra, M.M., Bigner, S.H., and Bigner, D.D. 1990. Anti-synthetic peptide antibody reacting at the fusion junction of deletion-mutant epidermal growth factor receptors in human glioblastoma. Proc. Natl. Acad. Sci. 87: 4207-4211.

Hunter, K. and Hatten, M. 1995. Radial glial cell transformation to astrocytes is bidirectional regulation by a diffusible factor in embryonic forebrain. Proc. Nat1. Acad. Sci. 92: 20612065.

Ichimura, K., Schmidt, E.E., Miyakawa, A., Goike, H.M., and Collins, V.P. 1998. Distinct patterns of deletion on 10p and 10q suggest involvement of multiple tumor suppressor genes in the development of astrocytic gliomas of different malignancy grades. Genes Chromosomes Cancer 22: 9-15.

Ino, Y., Betensky, R.A., Zlatescu, M.C., Sasaki, H., Macdonald, D.R., Stemmer-Rachamimov, A.O., Ramsay, D.A., Cairncross, J.G., and Louis, D.N. 2001. Molecular subtypes of anaplastic oligodendroglioma: Implications for patient management at diagnosis. Clin. Cancer. Res. 7: 839-845.

Jackson, M.W. and Berberich, S.J. 2000. MdmX protects p53 from Mdm2-mediated degradation. Mol. Cell Biol. 20: 10011007.

James, C.D., Carlbom, E., Dumanski, J.P., Hansen, M., Nordenskjold, M., Collins, V.P., and Cavenee., W.K. 1988. Clonal genomic alterations in glioma malignancy stages. Cancer Res. 48: 5546-5551.

James, C.D., He, J., Carlbom, E., Nordenskjold, M., Cavenee, W.K., and Collins, V.P. 1991. Chromosome 9 deletion mapping reveals interferon $\alpha$ and interferon $\beta$-1 gene deletions in human glial tumors. Cancer Res. 51: 1684-1688.

Johansson, C., Momma, S., Clarke, D., Risling, M., Lendahl, U., and Frisen, J. 1999. Identification of a neural stem cell in the 
adult mammalian central nervous system. Cell 96: 25-34.

Johnson, R.L., Rothman, A.L., Xie, J., Goodrich, L.V., Bare, J.W., Bonifas, J.M., Quinn, A.G., Myers, R.M., Cox, D.R., Epstein, E.H., et al. 1996. Human homolog of patched, a candidate gene for the basal cell nevus syndrome. Science 272: 16681671.

Kakita, A. and Goldman, J.E. 1999. Patterns and dynamics of SVZ cell migration in the postnatal forebrain: Monitoring living progenitors in slice preparations. Neuron 23: 461-472.

Kamijo, T., Zindy, F., Roussel, M.F., Quelle, D.E., Downing, J.R., Ashmun, R.A., Grosveld, G., and Sherr, C.J. 1997. Tumor suppression at the mouse INK4a locus mediated by the alternative reading frame product p19ARF. Cell 91: 649-659.

Kamijo, T., Bodner, S., van de Kamp, E., Randle, D.H., and Sherr, C.J. 1999. Tumor spectrum in ARF-deficient mice. Cancer Res. 59: 2217-2222.

Kaye, A.H. and Laws, E.R. 1995. Historical perspective. In Brain tumors (ed. A.H. Kaye and E.R. Laws, Jr.), pp. 3-8. Churchill Livingston, New York.

Kleihues, P. and Cavenee, W.K. 2000. World Health Organization classification of tumours of the nervous system. IARC/ WHO, Lyon.

Kraus, J.A., Koopmann, J., Kaskel, P., Maintz, D., Brandner, S., Schramm, J., Louis, D.N., Wiestler, O.D., and von Deimling, A. 1995. Shared allelic losses on chromosomes $1 \mathrm{p}$ and $19 \mathrm{q}$ suggest a commoon origin of oligodendroglioma and oligoastrocytoma. J. Neuropathol. Exp. Neurol. 54: 91-95.

Kubbutat, M.H., Jones, S.N., and Vousden, K.H. 1997. Regulation of p53 stability by Mdm2. Nature 387: 299-303.

Landau, B.J., Kwaan, H.C., Verrusio, E.N., and Brem, S.S. 1994. Elevated levels of urokinase-type plasminogen activator and plasminogen activator inhibitor type-1 in malignant human brain tumors. Cancer Res. 54: 1105-1108.

Lang, F.F., Miller, D.C., Koslow, M., and Newcomb, E.W. 1994. Pathways leading to glioblastoma multiforme: A molecular analysis of genetic alterations in 65 astrocytic tumors. $J$. Neurosurg. 81: 427-436.

Leavitt, B.R., Hernit-Grant, C.S., and Macklis, J.D. 1999. Mature astrocytes transform into transitional radial glia within adult mouse neocortex that supports directed migration of transplanted immature neurons. Exp. Neurol. 157: 43-57.

Levine, E.M., Close, J., Fero, M., Ostrovsky, A., and Reh, T.A. 2000. p27(Kipl) regulates cell cycle withdrawal of late multipotent progenitor cells in the mammalian retina. Dev. Biol. 219: 299-314.

Levison, S.W., Chuang, C., Abramson, B.J., and Goldman, J.E. 1993. The migrational patterns and developmental fates of glial precursors in the rat subventricular zone are temporally regulated. Development 119: 611-622.

Li, D.M. and Sun, H. 1998. PTEN/MMAC1/TEP1 suppresses the tumorigenicity and induces G1 cell cycle arrest in human glioblastoma cells. Proc. Natl. Acad. Sci. 95: 1540615411.

Li, J., Yen C., Liaw, D., Podsypanina, K., Bose, S., Want, S.I., Puc, J., Miliaresis, C., Rodgers, L., McCombie, R., et al. 1997. PTEN, a putative protein tyrosine phosphatase gene mutated in human brain, breast, and prostate cancer. Science 275: 1943-1947.

Liaw, D., Marsh, D.J., Li, J., Dahia, P.L., Wang, S.I., Zheng, Z., Bose, S., Call, K.M., Tsou, J.C., Peacocke, M., et al. 1997. Germline mutations of the PTEN gene in Cowden disease, an inherited breast and thyroid cancer syndrome. Nat. Genet. 16: 64-67.

Libermann, T.A., Nusbaum, H.R., Razon, N., Kris, R., Lax, I., Soreq, H., Whittle, N., Waterfield, M.D., Ullrich, A., and Schlessinger, J. 1985. Amplification, enhanced expression and possible rearrangement of EGF receptor gene in primary human brain tumours of glial origin. Nature 313: 144-147.

Lin, H., Bondy, M.L., Langford, L.A., Hess, K.R., Delclos, G.L., Wu, S., Chan, W., Pershouse, M.A., Yung, W.K., and Steck, P.A. 1998. Allelic deletion analyses of MMAC/PTEN and DMBT1 loci in gliomas: Relationship to prognostic significance. Clin. Cancer Res. 4: 2447-2454.

Liu, J., Bernabeau, R., Lu, A., and Sharp, F.R. 2000. Neurogenesis and gliogenesis in the postischemic brain. Neuroscientist 6: $362-370$.

Louis, D.N. 1994. The p53 gene and protein in human brain tumors. J. Neuropathol. Exp. Neurol. 53: 11-21.

Louis, D.N. and Cavenee, W. 1997. Molecular biology of central nervous system neoplasms. In Cancer: Principles and practice of oncology (eds. V.T. Devita and S. Hellman), pp. 20132022. Lippincott-Raven, Philadelphia.

. 2000. Molecular biology of central nervous system tumors. In Cancer: Principles and practice of oncology led. V.T. Devita and S. Hellman). Lippincott-Raven, Philadelphia.

Luetteke, N.C., Qiu, T.H., Peiffer, R.L., Oliver, P., Smithies, O., and Lee, D.C. 1993. TGF $\alpha$ deficiency results in hair follicle and eye abnormalities in targeted and waved-1 mice. Cell 73: $263-278$.

Luetteke, N.C., Phillips, H.K., Qiu, T.H., Copeland, N.G., Earp, H.S., Jenkins, N.A., and Lee, D.C. 1994. The mouse waved-2 phenotype results from a point mutation in the EGF receptor tyrosine kinase. Genes \& Dev. 8: 399-413.

Maehama, T. and Dixon, J.E. 1998. The tumor suppressor, PTEN/MMAC1, dephosphorylates the lipid second messenger, phosphatidylinositol 3,4,5-trisphosphate. J. Biol. Chem. 273: $13375-13378$.

Magavi, S.S., Leavitt, B.R., and Macklis, J.D. 2000. Induction of neurogenesis in the neocortex of adult mice. Nature 405: 951-955.

Maintz, D., Fiedler, K., Koopmann, J., Rollbrocker, B., Nechev, S., Lenartz, D., Stangl, A.P., Louis, D.N., Schramm, J., Wiestler, O.D., et al. 1997. Molecular genetic evidence for subtypes of oligoastrocytomas. I. Neuropathol. Exp. Neurol. 56: $1098-1104$.

Malkin, D., Li, F.P., Strong, L.C., Fraumeni, J.F., Jr., Nelson, C.E., Kim, D.H., Kassel, J., Gryka, M.A., Bischoff, F.Z., Tainsky, M.A., et al. 1990. Germ line p53 mutations in a familial syndrome of breast cancer, sarcomas, and other neoplasms. Science 250: 1233-1238.

McCormick, D. 1993. Secretion of cathepsin B by human gliomas in vitro. Neuropathol. Appl. Neurobiol. 19: 146-151.

McKeever, P.E., Davenport, R.D., and Shakui, P. 1991. Patterns of antigenic expression of human glioma cells. Crit. Rev. Neurobiol. 6: 119-147.

McKinnon, R.D., Matsui, T., Dubois-Dalcq, M., and Aaronson, S.A. 1990. FGF modulates the PDGF-driven pathway of oligodendrocyte development. Neuron 5: 603-614.

Miettinen, P.J., Berger, J.E., Meneses, J., Phung, Y., Pedersen, R.A., Werb, Z., and Derynck, R. 1995. Epithelial immaturity and multiorgan failure in mice lacking epidermal growth factor receptor. Nature 376: 337-341.

Migheli, A., Piva, R., Casolino, S., Atzori, C., Dlouhy, S.R., and Ghetti, B. 1999. A cell cycle alteration precedes apoptosis of granule cell precursors in the weaver mouse cerebellum. Am. J. Pathol. 155: 365-373.

Mignatti, P. and Rifkin, D.B. 1993. Biology and biochemistry of proteinases in tumor invasion. Physiol. Rev. 73: 161-195.

Millauer, B., Shawver, L.K., Plate, K.H., Risau, W., and Ullrich, A. 1994. Glioblastoma growth inhibited in vivo by a dominant-negative Flk-1 mutant. Nature 367: 576-579. 
Milner, R., Anderson, H.J., Rippon, R.F., McKay, J.S., Franklin, R.J., Marchionni, M.A., Reynolds, R., and Ffrench-Constant, C. 1997. Contrasting effects of mitogenic growth factors on oligodendrocyte precursor cell migration. Glia 19: 85-90.

Mishima, K., Nagane, M., Lin, H., Cavenee, W., and Huang, H.J.S. 1999. Expression of a specific mutant epidermal growth factor receptor mediates glioma cell invasion in vivo. Proc. Am. Assoc. Cancer Res.: 519.

Mitchell, E.L., White, G.R., Santibanez-Koref, M.F., Varley, J.M., and Heighway, J. 1995. Mapping of gene loci in the Q13-Q15 region of chromosome 12. Chromosome Res. 3: 261-262.

Miyazawa, K., Himi, T., Garcia, V., Yamagishi, H., Sato, S., and Ishizaki, Y. 2000. A role for p27/Kip1 in the control of cerebellar granule cell precursor proliferation. I. Neurosci. 20: 5756-5763.

Mollenhauer, J., Wiemann, S., Scheurlen, W., Korn, B., Hayashi, Y., Wilgenbus, K.K., von Deimling A., and Poustka, A. 1997. DMBT1, a new member of the SRCR superfamily, on chromosome 10q25.3-26.1 is deleted in malignant brain tumours. Nat. Genet. 17: 32-39.

Momand, J., Zambetti, G.P., Olson, D.C., George, D., and Levine, A.J. 1992. The $\mathrm{mdm}-2$ oncogene product forms a complex with the p53 protein and inhibits p53-mediated transactivation. Cell 69: 1237-1245.

Mueller, W., Lass, U., Herms, J., Kucheleister, K., Bergmann, M., and von Deimling, A. 2001. Clonal analysis in glioblastoma with epithelial differentation. Brain Pathol. 11: 39-43.

Mujtaba, T., Mayer-Proschel, M., and Rao, M.S. 1998. A common neural progenitor for the CNS and PNS. Dev. Biol. 200: $1-15$.

Myers, M.P., Stolarov, J.P., Eng, C., Li, J., Wang, S.I., Wigler, M.H., Parsons, R., and Tonks, N.K. 1997. P-TEN, the tumor suppressor from human chromosome 10q23, is a dual- specificity phosphatase. Proc. Natl. Acad. Sci. 94: 9052-9057.

Myers, M.P., Pass, I., Batty, I.H., Van der Kaay, J., Stolarov, J.P., Hemmings, B.A., Wigler, M.H., Downes, C.P., and Tonks, N.K. 1998. The lipid phosphatase activity of PTEN is critical for its tumor supressor function. Proc. Natl. Acad. Sci. 95: 13513-13518.

Nagane, M., Coufal, F., Lin, H., Bogler, O., Cavenee, W.K., and Huang, H.J. 1996. A common mutant epidermal growth factor receptor confers enhanced tumorigenicity on human glioblastoma cells by increasing proliferation and reducing apoptosis. Cancer Res. 56: 5079-5086.

Nagane, M., Levitzki, A., Gazit, A., Cavenee, W.K., and Huang, H.J. 1998. Drug resistance of human glioblastoma cells conferred by a tumor- specific mutant epidermal growth factor receptor through modulation of Bcl-XL and caspase-3-like proteases. Proc. Nat1. Acad. Sci. 95: 5724-5729.

Nakada, M., Nakamura, H., Ikeda, E., Fujimoto, N., Yamashita, J., Sato, H., Seiki, M., and Okada, Y. 1999. Expression and tissue localization of membrane-type 1,2, and 3 matrix metalloproteinases in human astrocytic tumors. Am. J. Pathol. 154: 417-428.

Nakagawa, T., Kubota, T., Kabuto, M., Sato, K., Kawano, H., Hayakawa, T., and Okada, Y. 1994. Production of matrix metalloproteinases and tissue inhibitor of metalloproteinases-1 by human brain tumors. J. Neurosurg. 81: 69-77.

Namiki, J. and Tator, C.H. 1999. Cell proliferation and nestin expression in the ependyma of the adult rat spinal cord after injury. J. Neuropathol. Exp. Neurol. 58: 489-498.

Neglia, J.P., Meadows, A.T., Robison, L.L., Kim, T.H., Newton, W.A., Ruymann, F.B., Sather, H.N., and Hammond, G.D. 1991. Second neoplasms after acute lymphoblastic leukemia in childhood. N. Engl. J. Med. 325: 1330-1336.
Nishikawa, R., Ji, X.D., Harmon, R.C., Lazar, C.S., Gill, G.N. Cavenee, W.K., and Huang, H.J. 1994. A mutant epidermal growth factor receptor common in human glioma confers enhanced tumorigenicity. Proc. Nat1. Acad. Sci. 91: 77277731.

Nishikawa, R., Furnari, F.B., Lin, H., Arap, W., Berger, M.S., Cavenee, W.K., and Su Huang, H.J. 1995. Loss of P16INK4 expression is frequent in high grade gliomas. Cancer Res. 55: $1941-1945$.

Olopade, O.I., Jenkins, R.B., Ransom, D.T., Malik, K., Pomykala, H., Nobori, T., Cowan, J.M., Rowley, J.D., and Diaz, M.O. 1992. Molecular analysis of deletions of the short arm of chromosome 9 in human gliomas. Cancer Res. 52: 25232529 .

Oumesmar, B., Vignais, L., and Baron-Van Evercooren, A. 1997. Developmental expression of platelet-derived growth factorreceptor in neurons and glial cells of the mouse CNS. J. Neurosci. 17: 125-.

Palmer, T.D., Takahashi, J., and Gage, F.H. 1997. The adult rat hippocampus contains primordial neural stem cells. Mol. Cell Neurosci. 8: 389-404.

Parr, M.J., Manome, Y., Tanaka, T., Wen, P., Kufe, D.W., Kaelin, W.G., and Fine, H.A. 1997. Tumor-selective transgene expression in vivo mediated by an E2F- responsive adenoviral vector. Nat. Med. 3: 1145-1149.

Picksley, S.M. and Lane, D.P. 1993. The p53-mdm2 autoregulatory feedback loop: A paradigm for the regulation of growth control by p53? BioEssays 15: 689-690.

Plate, K.H., Breier, G., Weich, H.A., and Risau, W. 1992. Vascular endothelial growth factor is a potential tumour angiogenesis factor in human gliomas in vivo. Nature 359: 845848.

Pohl, U., Smith, J.S., Tachibana, I., Ueki, K., Lee, H.K., Ramaswamy, S., Wu, Q., Mohrenweiser, H.W., Jenkins, R.B., and Louis, D.N. 2000. EHD2, EHD3, and EHD4 encode novel members of a highly conserved family of EH domain-containing proteins. Genomics 63: 255-262.

Pomerantz, J., Schreiber-Agus, N., Leigeois, N., Silverman, A., Alland, L., Chin, L., Potes, J., Chen, K., Orlow, I., Lee, H., et al. 1998. The Ink4a tumor suppressor gene product, p 19arf, interacts with MDM2 and neutralizes MDM2's inhibition of p53. Cell 92: 713-723.

Pringle, N.P., Mudhar, H.S., Collarini, E.J., and Richardson, W.D. 1992. PDGF receptors in the rat CNS: During late neurogenesis, PDGF $\alpha$-receptor expression appears to be restricted to glial cells of the oligodendrocyte lineage. Development 115: 535-551.

Quelle, D.E., Ashmun, R.A., Hannon, G.J., Rehberger, P.A., Trono, D., Richter, K.H., Walker, C., Beach, D., Sherr, C.J., and Serrano, M. 1995a. Cloning and characterization of murine p16INK4a and p15INK4b genes. Oncogene 11: 635-645.

Quelle, D.E., Zindy, F., Ashmun, R.A., and Sherr, C.J. 1995b. Alternative reading frames of the INK4a tumor suppressor gene encode two unrelated proteins capable of inducing cell cycle arrest. Cell 83: 993-1000.

Queva, C., Hurlin, P.J., Foley, K.P., and Eisenman, R.N. 1998 Sequential expression of the MAD family of transcriptional repressors during differentiation and development. Oncogene 16: 967-977.

Raffel, C., Jenkins, R.B., Frederick, L., Hebrink, D., Alderete, B., Fults, D.W., and James, C.D. 1997. Sporadic medulloblastomas contain PTCH mutations. Cancer Res. 57: 842-845.

Rakic, P. 1972. Mode of cell migration to the superficial layers of fetal monkey neocortex. J. Comp. Neurol. 145: 61-83.

Randerson-Moor, J.A., Harland, M., Williams, S., CuthbertHeavens, D., Sheridan, E., Aveyard, J., Sibley, K., Whitaker, 
L., Knowles, M., Newton Bishop, J., et al. 2001. A germline deletion of p14(ARF) but not CDKN2A in a melanoma-neural system tumour syndrome family. Hum. Mol. Genet. 10: $55-62$.

Ransom, D.T., Ritland, S.R., Kimmel, D.W., Moertel, C.A., Dahl, R.J., Scheithauer, B.W., Kelly, P.J., and Jenkins, R.B. 1992. Cytogenetic and loss of heterozygosity studies in ependymomas, pilocytic astrocytomas, and oligodendrogliomas. Genes Chromosomes Cancer 5: 348-356.

Reifenberger, G., Liu, L., Ichimura, K., Schmidt, E.E., and Collins, V.P. 1993. Amplification and overexpression of the MDM2 gene in a subset of human malignant gliomas without p53 mutations. Cancer Res. 53: 2736-273;9.

Reifenberger, G., Reifenberger, J., Ichimura, K., Meltzer, P.S., and Collins, V.P. 1994. Amplification of multiple genes from chromosomal region $12 \mathrm{q} 13-14$ in human malignant gliomas: Preliminary mapping of the amplicons shows preferential involvement of CDK4, SAS, and MDM2. Cancer Res. 54: 4299-4303.

Reifenberger, G., Kros, J.M., Burger, P.C., Louis, D.N., and Collins, V.P. 2000. Oligodendrogliomas and oligoastrocytomas. In World Health Organization classification of tumors of the nervous system (ed. A.H. Kaye and E.R. Laws, Jr.), pp. 56-67. IARC/WHO, Lyon.

Reilly, K.M., Loisel, D.A., Bronson, R.T., McLaughlin, M.E., and Jacks, T. 2000. Nf1;Trp53 mutant mice develop glioblastoma with evidence of strain-specific effects. Nat. Genet. 26: 109-113.

Reynolds, B.A. and Weiss, S. 1992. Generation of neurons and astrocytes from isolated cells in the central nervous system. Science 255: 1707-1710.

- 1996. Clonal and population analyses demonstrate that an EGF-responsive mammalian embryonic CNS precursor is a stem cell. Dev. Biol. 175: 1-13.

Ron, E., Modan B., Boice, J.D., Alfandary, E., Stovall, M., Chetrit, A., and Katz, L. 1988. Tumors of the brain and nervous system after radiotherapy in childhood. N. Engl. J. Med. 319: 1033-1039

Roy, N.S., Wang, S., Harrison-Restelli, C., Benraiss, A., Fraser, R.A., Gravel, M., Braun, P.E., and Goldman, S.A. 1999. Identification, isolation, and promoter-defined separation of mitotic oligodendrocyte progenitor cells from the adult human subcortical white matter. J. Neurosci. 19: 9986-9995.

Rubio, M.P., Correa, K.M., Ramesh, V., MacCollin, M.M., Jacoby, L.B., von Deimling, A., Gusella, J.F., and Louis, D.N. 1994. Analysis of the neurofibromatosis 2 gene in human ependymomas and astrocytomas. Cancer Res. 54: 45-47.

Sano, T., Lin, H., Chen, X., Langford, L.A., Koul, D., Bondy, M.L., Hess, K.R., Myers, J.N., Hong, Y.K., Yung, W.K., et al. 1999. Differential expression of MMAC/PTEN in glioblastoma multiforme: Relationship to localization and prognosis. Cancer Res. 59: 1820-1824.

Sato, T.N., Tozawa, Y., Deutsch, U., Wolburg-Buchholz, K., Fujiwara, Y., Gendron-Maguire, M., Gridley, T., Wolburg, H., Risau, W., and Qin, Y. 1995. Distinct roles of the receptor tyrosine kinases Tie-1 and Tie-2 in blood vessel formation. Nature 376: 70-74.

Scherer, H. 1940. The forms of growth in gliomas and their practical signficance. Brain 63: 1-35.

Schmidt, E.E., Ichimura, K., Reifenberger, G., and Collins, V.P. 1994. CDKN2 (p16/MTS1) gene deletion or CDK4 amplification occurs in the majority of glioblastomas. Cancer Res. 54: 6321-6324.

Schreiber-Agus, N. and DePinho, R.A. 1998. Repression by the Mad(Mxil)-Sin3 complex. BioEssays 20: 808-818.

Schreiber-Agus, N., Meng, Y., Hoang, T., Hou, H., Chen, K.,
Greenberg, R., Cordon-Cardo, C., Lee, H.W., and DePinho, R.A. 1998. Role of Mxil in ageing organ systems and the regulation of normal and neoplastic growth. Nature 393: 483-487.

Scolding, N.J., Rayner, P.J., and Compston, D.A. 1999. Identification of A2B5-positive putative oligodendrocyte progenitor cells and A2B5-positive astrocytes in adult human white matter. Neuroscience 89: 1-4.

Serrano, M., Lee, H., Chin, L., Cordon-Cardo, C., Beach, D., and DePinho, R.A. 1996. Role of the INK4a locus in tumor suppression and cell mortality. Cell 85: 27-37.

Shalaby, F., Rossant, J., Yamaguchi, T.P., Gertsenstein, M., Wu, X.F., Breitman, M.L., and Schuh, A.C. 1995. Failure of bloodisland formation and vasculogenesis in Flk-1-deficient mice. Nature 376: 62-66.

Shapiro, W.R., Green, S.B., Burger, P.C., Mahaley, M.S., Selker, R.G., VanGilder, J.C., Robertson, J.T., Ransohoff, J., Mealey, J., Strike, T.A., et al. 1989. Randomized trial of three chemotherapy regimens and two radiotherapy regimens in postoperative treatment of malignant glioma. Brain Tumor Cooperative Group Trial 8001. J. Neurosurg. 71: 1-9.

Sherr, C.J. 1996. Cancer cell cycles. Science 274: 1672-1677.

- 2000. The Pezcoller lecture: Cancer cell cycles revisited. Cancer Res. 60: 3689-3695.

Shoshan, Y., Nishiyama, A., Chang, A., Mork, S., Barnett, G. Cowell, J., Trapp, B., and Staugaitis, S. 1999. Expression of oligodendrocyte progenitor cell antigens by gliomas: Implications for the histogenesis of brain tumors. Med. Sci. 96: 10361-10366.

Sibilia, M., Steinbach, J.P., Stingl, L., Aguzzi, A., and Wagner, E.F. 1998. A strain-independent postnatal neurodegeneration in mice lacking the EGF receptor. EMBO J. 17: 719-731.

Sidransky, D., Mikkelsen, T., Schwechheimer, K., Rosenblum, M.L., Cavanee, W., and Vogelstein, B. 1992. Clonal expansion of p53 mutant cells is associated with brain tumour progression. Nature 355: 846-847.

Simpson, P.B. and Armstrong, R.C. 1999. Intracellular signals and cytoskeletal elements involved in oligodendrocyte progenitor migration. Glia 26: 22-35.

Small, R.K. 1992. Glial cell lineages in development and disease. In Disease of the nervous system: Clinical Neurobiology (eds. A.K. Ashurry, G.M. McKhann, and W.I. McDonald), pp. 72-86. W.B. Saunders Company, Philadelphia.

Smith, J.S., Tachibana, I., Pohl, U., Lee, H.K., Thanarajasigam, U., Portier, B.P., Ueki, K., Ramaswamy, S., Billings, S.J., Mohrenweiser, H.W., et al. 2000. A transcript map of the chromosome 19 q-arm tumor supressor region. Genomics, in press.

Soengas, M.S., Alarcon, R.M., Yoshida, H., Giaccia, A.J., Hakem, R., Mak, T.W., and Lowe, S.W. 1999. Apaf-1 and caspase-9 in p53-dependent apoptosis and tumor inhibition. Science 284: 156-159.

Soriano, E., Alvarado, R., Dumesnil, N., Del Rio, J., and Sotelo, C. 1997. Cajal-Retzius cells regulate the radial glia phenotype in the adult and developing cerebellum and alter granule cell migration. Neuron 18: 563-577.

Stambolic, V., Suzuki, A., de la Pompa, J.L., Brothers, G.M., Mirtsos, C., Sasaki, T., Ruland, J., Penninger, J.M., Siderovski, D.P., and Mak, T.W. 1998. Negative regulation of $\mathrm{PKB} /$ Akt-dependent cell survival by the tumor suppressor PTEN. Cell 95: 29-39.

Steck, P., Perhouse, M.A., Jasser, S.A., Yung, W.K.A., Lin, H., Ligon, A.H., Langford, L.A., Baumgard, M.L., Hattier, J., Frye, C., et al. 1997. Identification of a candidate tumour suppressor gene, MMAC 1, at chromosome 10q23.3 that is mutated in multiple advanced cancers. Nat. Genet. 15: 356- 
362.

Stott, F.J., Bates, S., James, M.C., McConnell, B.B., Starborg, M., Brookes, S., Palmero, I., Ryan, K., Hara, E., Vousden, K.H., et al. 1998. The alternative product from the human CDKN2A locus, p14(ARF), participates in a regulatory feedback loop with p53 and MDM2. EMBO J. 17: 5001-5014.

Suri, C., Jones, P.F., Patan, S., Bartunkova, S., Maisonpierre, P.C., Davis, S., Sato, T.N., and Yancopoulos, G.D. 1996. Requisite role of angiopoietin-1, a ligand for the TIE2 receptor, during embryonic angiogenesis. Cell 87: 1171-1180.

Takagi, Y., Nozaki, K., Takahashi, J., Yodoi, J., Ishikawa, M., and Hashimoto, N. 1999. Proliferation of neuronal precursor cells in the dentate gyrus is accelerated after transient forebrain ischemia in mice. Brain Res. 831: 283-287.

Takito, J., Yan, L., Ma, J., Hikita, C., Vijayakumar, S., Warburton, D., and Al-Awqati, Q. 1999. Hensin, the polarity reversal protein, is encoded by $D M B T 1$, a gene frequently deleted in malignant gliomas. Am. J. Physiol. 277: F277-289.

Tamura, M., Gu, J., Matsumoto, K., Aota, S., Parsons, R., and Yamada, K.M. 1998. Inhibition of cell migration, spreading, and focal adhesions by tumor suppressor PTEN. Science 280: $1614-1617$.

Teng, D.H., Hu, R., Lin, H., Davis, T., Iliev, D., Frye, C., Swedlund, B., Hansen, K.L., Vinson, V.L., Gumpper, K.L., et al. 1997. MMAC1/PTEN mutations in primary tumor specimens and tumor cell lines. Cancer Res. 57: 5221-5225.

Threadgill, D.W., Dlugosz, A.A., Hansen, L.A., Tennenbaum, T., Lichti, U., Yee, D., LaMantia, C., Mourton, T., Herrup, K., Harris, R.C., et al. 1995. Targeted disruption of mouse EGF receptor: Effect of genetic background on mutant phenotype. Science 269: 230-234.

Tikoo, R., Osterhout, D.J., Casaccia-Bonnefil, P., Seth, P., Koff, A., and Chao, M.V. 1998. Ectopic expression of p27Kip1 in oligodendrocyte progenitor cells results in cell-cycle growth arrest. J. Neurobiol. 36: 431-440.

Tsai, R.Y. and McKay, R.D. 2000. Cell contact regulates fate choice by cortical stem cells. J. Neurosci. 20: 3725-3735.

Ueki, K., Ono, Y., Henson, J.W., Efird, J.T., von Deimling, A., and Louis, D.N. 1996. CDKN2/p16 or RB alterations occur in the majority of glioblastomas and are inversely correlated. Cancer Res. 56: 150-153.

Uhm, J.H., Dooley, N.P., Villemure, J.G., and Yong, V.W. 1997. Mechanisms of glioma invasion: Role of matrix-metalloproteinases. Can. J. Neurol. Sci. 24: 3-15.

Uhrbom, L., Hesselager, G., Ostman, A., Nister, M., and Westermark, B. 2000. Dependence of autocrine growth factor stimulation in platelet-derived growth factor-B-induced mouse brain tumor cells. Int. J. Cancer 85: 398-406.

Vazquez, F., Ramaswamy, S., Nakamura, N., and Sellers, W.R. 2000. Phosphorylation of the PTEN tail regulates protein stability and function. Mol. Cell Biol. 20: 5010-5018.

Voigt, T. 1989. Development of glial cells in the cerebral wall of ferrets: Direct tracing of their transformation from radial glia into astrocytes. J. Comp. Neurol. 289: 74-88.

von Deimling, A., Eibl, R.H., Ohgaki, H., Louis, D.N., von Ammon, K., Petersen, I., Kleihues, P., Chung, R.Y., Wiestler, O.D., and Seizinger, B.R. 1992a. p53 mutations are associated with $17 \mathrm{p}$ allelic loss in grade II and grade III astrocytoma. Cancer Res. 52: 2987-2990.

von Deimling, A., Louis, D.N., von Ammon, K., Petersen, I., Hoell, T., Chung, R.Y., Martuza, R.L., Schoenfeld, D.A., Yasargil, M.G., Wiestler, O.D., et al. 1992b. Association of epidermal growth factor receptor gene amplification with loss of chromosome 10 in human glioblastoma multiforme. J. Neurosurg. 77: 295-301.

von Deimling, A., von Ammon, K., Schoenfeld, D., Wiestler, O.,
Seizinger, B., and Louis, D. 1993. Subsets of glioblastoma mulitforme defined by molecular genetic analysis. Brain Pathol. 3: 19-26.

von Deimling, A., Bender, B., Jahnke, R., Waha, A., Kraus, J., Albrecht, S., Wellenreuther, R., Fassbender, F., Nagel, J., Menon, A.G., et al. 1994. Loci associated with malignant progression in astrocytomas: A candidate on chromosome 19q. Cancer Res. 54: 1397-1401.

Wallace, V.A. 1999. Purkinje-cell-derived Sonic hedgehog regulates granule neuron precursor cell proliferation in the developing mouse cerebellum. Curr. Biol. 9: 445-448.

Wang, S.I., Puc, J., Li, J., Bruce, J.N., Cairns, P., Sidransky, D., and Parsons, R. 1997. Somatic mutations of PTEN in glioblastoma multiforme. Cancer Res. 57: 4183-4186.

Weber, J.D., Hu, W., Jefcoat, S.C., Raben, D.M., and Baldassare, J.J. 1997. Ras-stimulated extracellular signal-related kinase 1 and RhoA activities coordinate platelet-derived growth factor-induced G1 progression through the independent regulation of cyclin D1 and p27. J. Biol. Chem. 272: 32966-32971.

Wechsler, D.S., Shelly, C.A., Petroff, C.A., and Dang, C.V. 1997. MXI1, a putative tumor suppressor gene, suppresses growth of human glioblastoma cells. Cancer Res. 57: 4905-4912.

Wechsler-Reya, R.J. and Scott, M.P. 1999. Control of neuronal precursor proliferation in the cerebellum by Sonic hedgehog. Neuron 22: 103-114.

Weickert, C.S. and Blum, M. 1995. Striatal TGF- $\alpha$ : Postnatal developmental expression and evidence for a role in the proliferation of subependymal cells. Brain Res. Dev. 86: 203216.

Weinstein, D.E., Burrola, P., and Kilpatrick, T.J. 1996. Increased proliferation of precursor cells in the adult rat brain after targeted lesioning. Brain Res. 743: 11-16.

Weissenberger, J., Steinbach, J.P., Malin, G., Spada, S., Rulicke, T., and Aguzzi, A. 1997. Development and malignant progression of astrocytomas in GFAP-v-src transgenic mice. Oncogene 14: 2005-2013.

Willis, A.I., Fuse, S., Wang, X.J., Chen, E., Tuszynski, G.P., Sumpio, B.E., and Gahtan, V. 2000. Inhibition of phosphatidylinositol 3-kinase and protein kinase $\mathrm{C}$ attenuates extracellular matrix protein-induced vascular smooth muscle cell chemotaxis. J. Vasc. Surg. 31: 1160-1167.

Wolswijk, G., Riddle, P.N., and Noble, M. 1991. Platelet-derived growth factor is mitogenic for $\mathrm{O}-2 \mathrm{~A}$ adult progenitor cells. Glia 4: 495-503.

Wong, A.J., Bigner, S.H., Bigner, D.D., Kinzler, K.W., Hamilton, S.R., and Vogelstein, B. 1987. Increased expression of the epidermal growth factor receptor gene in malignant gliomas is invariably associated with gene amplification. Proc. Natl. Acad. Sci. 84: 6899-6903.

Wong, A.J., Ruppert, J.M., Bigner, S.H., Grzeschik, C.H., Humphrey, P.A., Bigner, D.S., and Vogelstein, B. 1992. Structual alterations of the epidermal growth factor receptor gene in human gliomas. Proc. Natl. Acad. Sci. 89: 2965-2969.

Wu, X., Senechal, K., Neshat, M.S., Whang, Y.E., and Sawyers, C.L.. 1998. The PTEN/MMAC1 tumor suppressor phosphatase functions as a negative regulator of the phosphoinositide 3-kinase/Akt pathway. Proc. Natl. Acad. Sci. 95: 1558715591.

Yamamoto, M., Sawaya, R., Mohanam, S., Rao, V.H., Bruner, J.M., Nicolson, G.L., and Rao, J.S. 1994. Expression and localization of urokinase-type plasminogen activator receptor in human gliomas. Cancer Res. 54: 5016-5020.

Yarden, Y. and Schlessinger, J. 1987. Epidermal growth factor induces rapid, reversible aggregation of the purified epidermal growth factor receptor. Biochemistry 26: 1443-1451.

Yeh, H.J., Ruit, K.G., Wang, Y.X., Parks, W.C., Snider, W.D., and 
Deuel, T.F. 1991. PDGF A-chain gene is expressed by mammalian neurons during development and in maturity. Cell 64: 209-216.

Yeh, H.J., Silos-Santiago, I., Wang, Y.X., George, R.J., Snider, W.D., and Deuel, T.F. 1993. Developmental expression of the platelet-derived growth factor $\alpha$-receptor gene in mammalian central nervous system. Proc. Natl. Acad. Sci. 90: 1952-1956.

Yong, T., Ueki, K., Chou, D., Reeves, S.A., von Deimling, A., Gusella, J.F., Mohrenweiser, H.W., Buckler, A.J., and Louis, D.N. 1995. Cloning of a highly conserved human protein serine-threonine phosphatase gene from the glioma candidate region on chromosome 19q13.3. Genomics 29: 533-536.

Zagzag, D., Amirnovin, R., Greco, M.A., Yee, H., Holash, J., Wiegand, S.J., Zabski, S., Yancopoulos, G.D., and Grumet, M. 2000. Vascular apoptosis and involution in gliomas precede neovascularization: A novel concept for glioma growth and angiogenesis. Lab. Invest. 80: 837-849.

Zauberman, A., Flusberg, D., Haupt, Y., Barak, Y., and Oren, M. 1995. A functional p53-responsive intronic promoter is contained within the human $m d m 2$ gene. Nucleic Acids Res. 23: 2584-2592.

Zhang, S.C., Ge, B., and Duncan, I.D. 1999. Adult brain retains the potential to generate oligodendroglial progenitors with extensive myelination capacity. Proc. Natl. Acad. Sci. 96: 4089-4094.

Zhang, Y., Xiong, Y., and Yarbrough, W.G. 1998. ARF promotes MDM2 degradation and stabilizes p53: ARF-INK4a locus deletion impairs both the $\mathrm{Rb}$ and $\mathrm{p} 53$ tumor suppression pathways. Cell 92: 725-734.

Zhu, G., Mehler, M.F., Mabie, P.C., and Kessler, J.A. 1999. Developmental changes in progenitor cell responsiveness to cytokines. J. Neurosci. Res. 56: 131-145. 


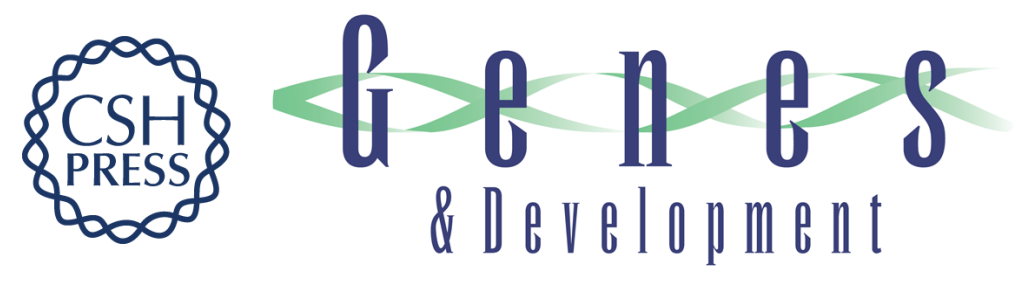

\section{Malignant glioma: genetics and biology of a grave matter}

Elizabeth A. Maher, Frank B. Furnari, Robert M. Bachoo, et al.

Genes Dev. 2001, 15:

Access the most recent version at doi:10.1101/gad.891601

References This article cites 208 articles, 84 of which can be accessed free at: http://genesdev.cshlp.org/content/15/11/1311.full.html\#ref-list-1

License

Email Alerting Receive free email alerts when new articles cite this article - sign up in the box at the top Service right corner of the article or click here.

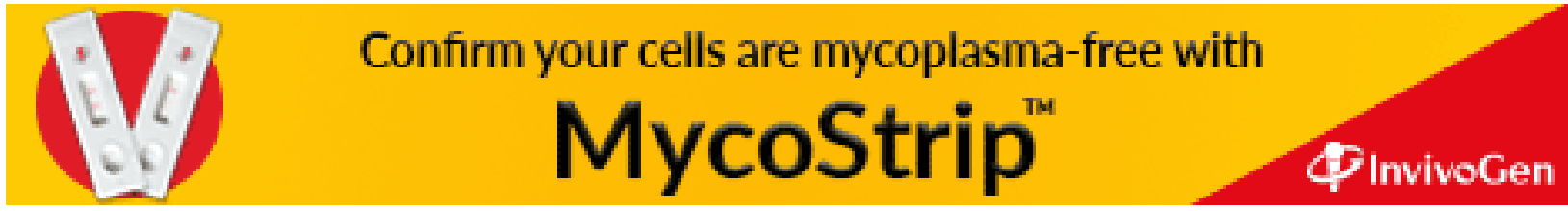

